\title{
Phytopathology
}

\section{Citrus Huanglongbing: A Newly Relevant Disease Presents Unprecedented Challenges}

\author{
Nian Wang and Pankaj Trivedi
}

Citrus Research and Education Center, Department of Microbiology and Cell Science, University of Florida, Lake Alfred 33850.

Current address for P. Trivedi: Hawkesbury Institute for the Environment, University of Western Sydney, Hawkesbury Campus (Richmond), Penrith South DC, NSW 2751, Australia.

Accepted for publication 19 February 2013

\begin{abstract}
Wang, N., and Trivedi, P. 2013. Citrus huanglongbing: A newly relevant disease presents unprecedented challenges. Phytopathology 103:652-665.

Citrus huanglongbing (HLB) is one of the oldest citrus diseases and has been known for over a century. HLB is caused by 'Candidatus Liberibacter' spp. that are phloem-limited, fastidious $\alpha$-proteobacteria and infect hosts in different Kingdoms (i.e., Animalia and Plantae). When compared with well-characterized, cultivatable plant-pathogenic Gram-negative bacteria, the interactions of uncultured insect-vectored plantpathogenic bacteria, including ' $\mathrm{Ca}$. Liberibacter' spp., with their hosts remain poorly understood. ' $\mathrm{Ca}$. Liberibacter' spp. have been known to cause HLB, which has been rapidly spreading worldwide, resulting in dramatic economic losses. HLB presents an unprecedented challenge to citrus production. In this review, we focus on the most recent research on citrus, 'Candidatus Liberibacter asiaticus', and psyllid interactions, specifically considering the following topics: evolutionary relationships among ' $\mathrm{Ca}$. Liberibacter' spp., genetic diversity, host range, genome analysis, transmission, virulence mechanisms, and the ecological importance of HLB. Currently, no efficient management strategy is available to control HLB, although some promising progress has been made. Further studies are needed to understand citrus, ' $\mathrm{Ca}$. L. asiaticus', and psyllid interactions to design innovative management strategies. Although HLB has been problematic for over a century, we can only win the battle against HLB with a coordinated and deliberate effort by the citrus industry, citrus growers, researchers, legislatures, and governments.
\end{abstract}

Additional keywords: agroecosystem, evolution.

Citrus huanglongbing (HLB) is one of the oldest diseases in citrus and has been known in East Asia for over a century $(20,30,61)$. However, this disease was largely ignored until its recent introduction to the Americas. HLB poses an unprecedented challenge in newly infected citrus production areas.

HLB is characterized by blotchy mottling with green islands on leaves. Infected shoots are stunted, and the branches gradually die as the disease progresses. Fruit from diseased trees may be small and lopsided, with poor coloration (Fig. 1). HLB greatly damages the citrus industry by shortening the trees' lifespan and reducing fruit yield and quality characteristics, such as total soluble solids (TSS) content, acidity, and the TSS/acidity ratio (Fig. 1) (14,31, 137). HLB can debilitate the productive capacity of citrus trees, with reported losses of 30 to $100 \%$ (10). It has also been observed that HLB-diseased trees are more adversely affected by extremes of temperature and moisture than are healthy trees. Consequently, symptoms of stress (e.g., excessive leaf loss and premature fruit drop) occur in HLB-diseased trees. This stress intolerance is

Corresponding author: N. Wang; E-mail address: nianwang@ufl.edu

http://dx.doi.org/10.1094/PHYTO-12-12-0331-RVW

(C) 2013 The American Phytopathological Society thought to result partially from a loss of fibrous root function. Recently, Johnson and colleagues (76) surveyed the root status of HLB-affected trees. HLB-diseased, 4-year-old 'Valencia' orange trees showed a 30 and $37 \%$ reduction in fibrous root mass density for presymptomatic and symptomatic trees, respectively, compared with healthy trees (76).

All commercial citrus species and scion cultivars are susceptible to HLB infection regardless of rootstock (20). However, a recent analysis of 30 different genotypes of citrus to Florida isolates of 'Candidatus Liberibacter asiaticus' indicated that there are differences in host response to HLB (e.g., sensitive, moderately tolerant, and tolerant). The sensitive genotypes include Citrus halimii, 'Nules' clementine mandarin, Valencia sweet orange, 'Madam Vinous' sweet orange, 'Duncan' grapefruit, 'Ruby' red grapefruit, and 'Minneola' tangelo whereas the most tolerant genotypes are Eureka lemon, Persian lime, Carrizo citrange, and Severinia buxifolia (52).

HLB is widespread in most citrus areas of Asia, Africa, and the Americas. Importantly, HLB and the Asian citrus psyllid (ACP) (Diaphorina citri, vector of ' $\mathrm{Ca}$. L. asiaticus') are expanding to new citrus production areas (Fig. 2). In the past 14 years, the ACP has been found in Florida, Texas, California, Arizona, Hawaii, Louisiana, Georgia, and Alabama in the United States, as well as 
in parts of South and Central America, Mexico, and the Caribbean. Meanwhile, HLB has been identified in Florida (2005), Louisiana (2008), South Carolina (2009), Louisiana (2008), Georgia (2009), and, most recently, in Texas and California (2012) of the United States; it has also been discovered in Cuba, Belize, Jamaica, Mexico, and other countries in the Caribbean.

HLB is associated with a phloem-limited fastidious $\alpha$-proteobacterium given provisional Candidatus status ('Candidatus Liberobacter' spp. later changed to 'Candidatus Liberibacter' spp.) (Fig. 2) in its nomenclature $(57,75)$. Currently, three species of ' $C a$. Liberibacter' are recognized in trees with HLB disease based on $16 \mathrm{~S}$ rDNA sequence: ' $C a$. L. asiaticus', ' $C a$. L. africanus', and ' $C a$. L. americanus'. Circumstantial evidence indicates that HLB is caused by ' $C a$. Liberibacter' spp., although Koch's postulates have not been fulfilled due to the difficulty in culturing the bacterium, as reported previously (20). Two recent studies of bacterial diversity associated with HLB disease further support that ' $C a$. L. asiaticus' is the sole pathogen responsible for HLB in Florida $(117,141)$. In a study by Sagaram et al. (117), ' $C a$. L. asiaticus' was detected at a very low level in asymptomatic plants but was $>200$ times more abundant in symptomatic plants based on PhyloChip analysis. The PhyloChip analysis results were further verified by sequencing of the $16 \mathrm{~S}$ rRNA gene clone libraries, which indicated the dominance of ' $\mathrm{Ca}$. L. asiaticus' in symptomatic leaves. ' $C a$. L. asiaticus' is absent or present in small populations in asymptomatic plants. In a study by Tyler et al. (141), three next-generation high-throughput sequencing platforms (454, Solexa, and SOLiD) were used to obtain metagenomic DNA sequences from the phloem tissue of HLB-diseased citrus trees. Only ' $\mathrm{Ca}$. L. asiaticus' was identified from the phloem tissue. This phloem metagenomic DNA provided further evidence to verify the presence of ' $\mathrm{Ca}$. L. asiaticus' in infected tissues, and no other disease agents were present in the phloem. Phytoplasma has been found in trees showing HLB-like symptoms in Brazil and China $(27,128)$. However, phytoplasma has not been identi- fied in HLB-diseased trees in Florida $(117,141)$. In addition, no phytoplasma has been reported in psyllids collected from Indonesia and Florida $(103,126)$. Based on these current studies, the research community agrees that HLB is caused by ' $\mathrm{Ca}$. Liberibacter' spp., which distinguishes HLB from the disease caused by phytoplasma.

Evolutionary relationships between ' $\mathrm{Ca}$. Liberibacter' spp. and related bacteria. All ' $\mathrm{Ca}$. Liberibacter' spp. belong to the gram-negative $\alpha$-proteobacteria in the family Rhizobiaceae. The taxonomy of the ' $\mathrm{Ca}$. Liberibacter' spp. is based on the 16S rRNA gene sequence rather than traditional methods such as morphology, growth, enzymatic activity, metabolism, and DNA-DNA hybridization (84) due to the difficulty of culturing the bacteria. Phylogenetic analysis has shown that ' $\mathrm{Ca}$. L. asiaticus' is an "early branching member" of Rhizobiaceae, and the long branch of ' $\mathrm{Ca}$. L. asiaticus' in the phylogenetic tree suggests rapid evolution of this pathogen (40). The recent discoveries of ' $C a$. L. europaeus' and ' $\mathrm{Ca}$. L. solanacearum' suggest that ' $\mathrm{Ca}$. Liberibacter' spp. may be widespread in psyllids and their host plants. A bacterial isolate initially isolated from the bunchy top diseased hybrid mountain papaya (Carica stipulate $\times C$. pubescens) is recently characterized as the first cultured member of genus Liberibacter and is named as Liberibacter crescens (89). Further studies are needed to investigate whether ' $\mathrm{Ca}$. Liberibacter' spp. occur in other psyllid species and their host plants.

Interestingly, all ' $C a$. Liberibacter' spp. are phloem restricted and transmitted by psyllids, except that $L$. crescens is reported to be present in the periphery of phloem and the association of the bacterium with insects has not yet been determined (89). It is most likely that ' $\mathrm{Ca}$. Liberibacter' spp. evolved from the same ancestor in the Rhizobiaceae family through adaptive, diversifying, and reductive evolutionary processes that occur during host adaptation (129). This evolution is possible due to the intimate relationship between members of the Rhizobiaceae family and plant roots (54). The intimate associations of ' $\mathrm{Ca}$. Liberibacter'
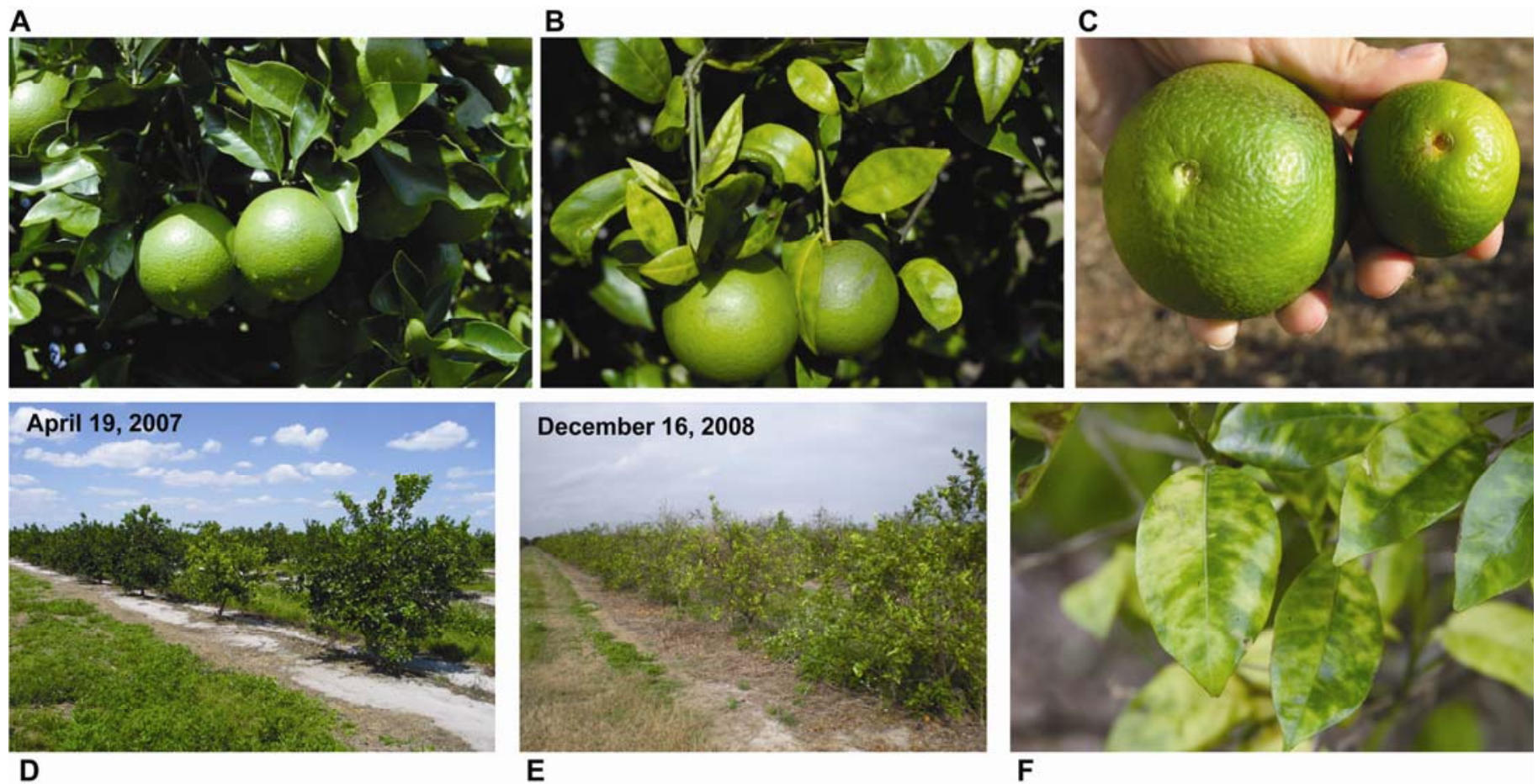

\section{FIGURE 1}

Huanglongbing (HLB) causes dramatic symptoms in citrus. A, Healthy 'Valencia' sweet orange (Citrus sinensis); B, Valencia with HLB disease; C, typical fruit from healthy trees (left) and from severely diseased HLB trees (right); $\mathbf{D}$, citrus grove before HLB; $\mathbf{E}$, citrus grove after HLB infection; $\mathbf{F}$, typical blotchy mottling with green islands on leaves from HLB trees (C, D, E, and F: courtesy of M. Irey, U.S. Sugar Corp.). 
spp. with plants as endophytes predispose them to frequent encounters with herbivorous insects, providing ' $\mathrm{Ca}$. Liberibacter' spp. with ample opportunities to colonize and eventually evolve alternative associations with insects (110). The genome sizes of the bacteria closely related to ' $\mathrm{Ca}$. Liberibacter' spp. range between $3.4 \mathrm{Mb}$ (Agrobacterium sp. H13-3), 5.7 Mb (Agrobacterium tumefaciens C58), 6.3 Mb (A. vitis S4), 6.5 Mb (Rhizobium etli CFN 42), 6.7 Mb (Sinorhizobium meliloti 1021), and $7.3 \mathrm{Mb}$ (A. radiobacter $\mathrm{K} 84$ ); in contrast, the much-reduced genome size of ' $\mathrm{Ca}$. Liberibacter' spp. ranges from $1.23 \mathrm{Mb}$ for 'Ca. L. asiaticus' and $1.26 \mathrm{Mb}$ for ' $C a$. L. solanacearum' to $1.5 \mathrm{Mb}$ for $L$. crescens (89). The reduced genome size and low GC content of ' $\mathrm{Ca}$. L. asiaticus' and ' $\mathrm{Ca}$. L. solanacearum' are hypothesized to be the result of stable and nutrient-rich environments and attenuated purifying selection due to small population sizes and strong bottleneck effects $(105,107,150)$. Hartung et al. (67) compared the genome of ' $\mathrm{Ca}$. L. asiaticus' with other members of Rhizobiales, including S. meliloti, Bradyrhizobium japonicum (both $\mathrm{N}_{2}$-fixing endosymbionts), A. tumefaciens (plant pathogen), and Bartonella japonicum (an intracellular mammalian pathogen). Whole-genome comparisons have identified at least 50 clusters of conserved microsyntenous orthologous genes (MOGs) found on the chromosomes of all five metabolically diverse species (67). The existence of so many MOGs in these interspecific genomic comparisons reflects the underlying evolutionary relationships among these species. Because $S$. meliloti is a close phylogenetic relative of ' $\mathrm{Ca}$. L. asiaticus', it is likely that the two bacteria deploy a similar repertoire of mechanisms for avoiding defenses elicited in host plant cells by their invasion or, in the case of beneficial root nodule bacteria, recruitment or "welcome entry"
(87). In all, $\approx 182$ pSymA (megaplasmid of S. meliloti carrying nonessential "accessory" genes involved in maintaining intimate intracellular plant interactions with host alfalfa) encoded proteins have sequence similarity ( $\leq \mathrm{E}-10)$ with ' $\mathrm{Ca}$. L. asiaticus' proteins (87). These proteins are involved in amino acid uptake, the cell surface structure, chaperonins, electron transport, the export of bioactive molecules, cellular homeostasis, the regulation of gene expression, signal transduction, and the synthesis of amino acids and metabolic cofactors. The presence of multiple orthologs is consistent with the hypothesis that these proteins may be of particular importance in host-microbe interactions, and their duplication likely facilitates their ongoing evolution (87).

The transition between hosts subjects ' $\mathrm{Ca}$. L. asiaticus' to a dramatic change in habitat, even though the sugar concentrations in the vector hemolymph and plant phloem are comparable (106). The phloem seems to be a more suitable environment for ' $\mathrm{Ca}$. L. asiaticus' compared with the psyllid 's hemolymph. Recently, we used quantitative reverse-transcription polymerase chain reaction (PCR) to compare the gene expression of ' $\mathrm{Ca}$. L. asiaticus' in planta and in psyllid. Of the 381 genes that were analyzed, 182 were upregulated in planta compared with in psyllid $(P<0.05)$, 16 genes were upregulated in psyllid $(P<0.05)$, and 183 genes showed no significant difference $(P=0.05)$ between expression in planta and expression in psyllid. Our study indicated that the expression of ' $\mathrm{Ca}$. L. asiaticus' genes involved in transcriptional regulation, the transport system, the secretion system, flagellar assembly, the metabolic pathway, and stress resistance was significantly changed in a host-specific manner to adapt to the distinct environments of plant and insect (154). The biased gene induction of ' $C a$. L. asiaticus' in planta compared with in psyllid suggests
A

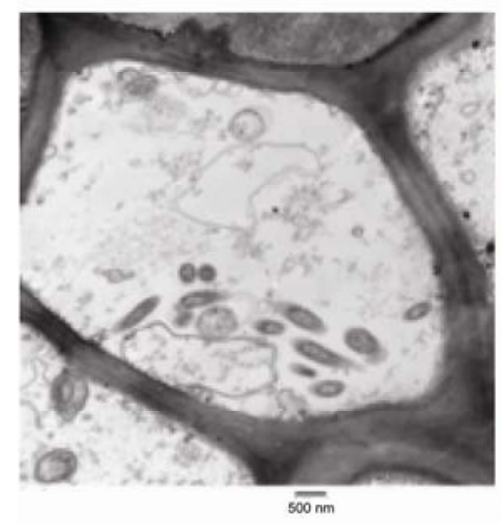

B

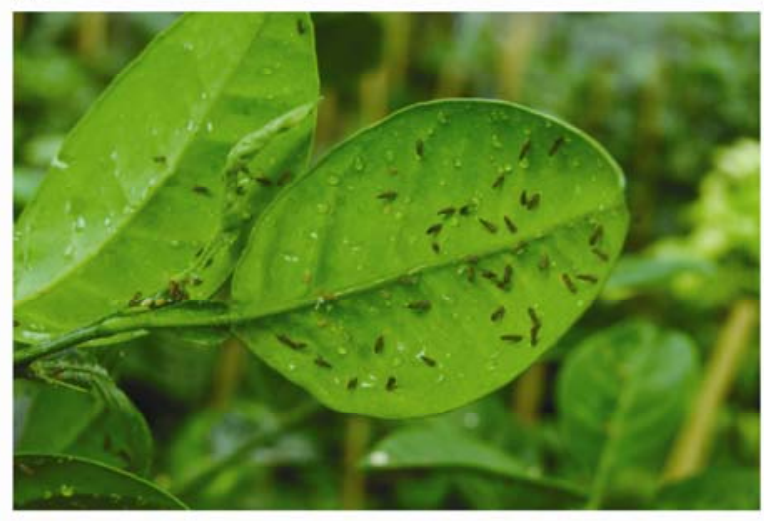

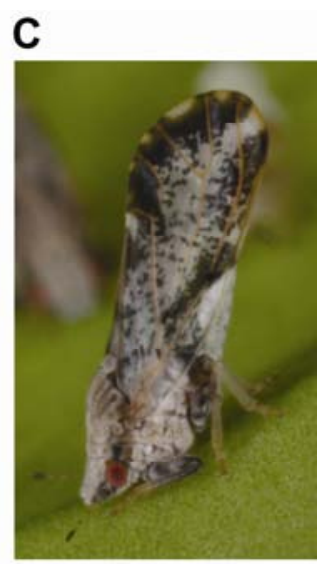
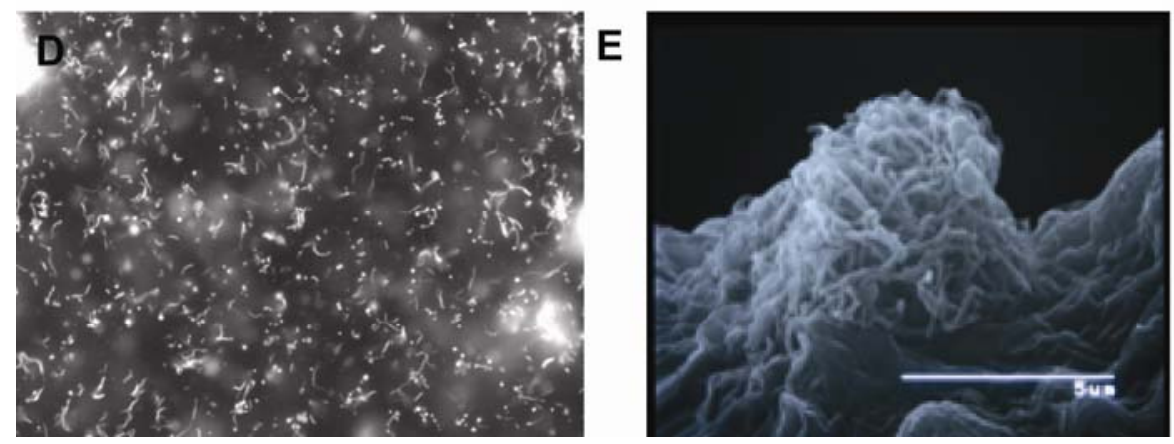

\section{FIGURE 2}

The 'Candidatus Liberibacter asiaticus' life-cycle involves the replication of the microbe in plants and psyllids. A, Transmission electron microscopy picture of 'Ca. L. asiaticus' in the phloem of citrus (Courtesy of S. Y. Folimonova and D. Achor, Citrus Research and Education Center [CREC], University of Florida [UF]); B and C, Asian citrus psyllid (Diaphorina citri) feeding on citrus plants (C courtesy of M. Rogers, CREC, UF); D, scanning electron micrograph of 'Ca. L. asiaticus' on the exterior surface of the psyllid midgut (courtesy of M. Davis, CREC, UF); E, 'Ca. L. asiaticus' acquired from psyllids stained with a DNA-binding fluorochrome SYTO 13 (courtesy of M. Davis). 
that it is more active in planta compared with a passive and idle status in psyllid. In addition, it has been suggested that ' $\mathrm{Ca}$. L. asiaticus' forms a biofilm in the psyllid (Fig. 2), whereas biofilm formation has not been reported for ' $\mathrm{Ca}$. L. asiaticus' in planta. It is possible that the biofilm formation of ' $\mathrm{Ca}$. L. asiaticus' in the psyllid is either stress induced, as reported for other bacteria such as Pseudomonas aeruginosa (60), or adjusts its physical status to be suitable for psyllid transmission. Together, these pieces of evidence suggest the vector role of psyllids for ' $\mathrm{Ca}$. L. asiaticus' to its ultimate plant host. It remains to be determined how ' $\mathrm{Ca}$. L. asiaticus' interacts with psyllids in the short lifespan of the vector.

Interestingly, ' $\mathrm{C} a$. L. asiaticus' lacks a complete restrictionmodification system $(40,92)$. Thus, ' $C a$. L . asiaticus' is vulnerable to prophage integration, as shown by the presence of several phage-derived gene sequences within its genome. This could result in an enhanced rate of evolution in ' $C a$. L. asiaticus' through phage-mediated recombination events (92). In addition, ' $C a$. L. asiaticus' lacks three proteins involved in DNA replication and repair that are present in ' $\mathrm{Ca}$. L. solanacearum': LexA, DnaE, and RadC. Consequently, it has been suggested that ' $C a$. L. asiaticus' (40) rapidly evolves, which is typical of host-restricted symbionts and pathogens, due to the elevated genetic drift resulting from both population bottlenecks and relaxed selection on many genes $(40,105)$. A geographic range of ' $\mathrm{Ca}$. L. asiaticus' variants based on phylogenetic analysis has been reported, although no differences in phenotype have been reported $(15,36)$.

Genetic diversity. The detection of genetic diversity within pathogen populations is fundamental for ecological and epidemiological studies of a disease. The genetic structure within a given pathogen is an indispensable prerequisite for determining sources of infection and risk management for diseases. In previous studies, monoclonal antibodies directed against ' $\mathrm{Ca}$. L. asiaticus' isolates from different geographical locations have been shown to react with one or several isolates but none of the antibodies react with all of the isolates $(55,58)$. Gao et al. (55) classified $11^{\prime} \mathrm{Ca}$. L. asiaticus' isolates from different geographical locations into six different serotypes, suggesting that there is significant genomic variation among isolates. In further studies, molecular techniques provided useful complementary tools for the identification and genetic characterization of ' $\mathrm{Ca}$. L. asiaticus'. The genetic diversity, primarily at several loci in the $r r s$ and $r p l$ genes and in the omp and rpoB loci of HLB-associated Liberibacters, is well documented $(15,38,53,57)$. Bastianel et al. (15) used an ompbased PCR-restriction fragment length polymorphism to analyze the genetic variability of ' $\mathrm{Ca}$. L. asiaticus' isolates and showed that, even within a given region, several different variants exist. The omp gene was further assayed by various restriction endonucleases to investigate the genetic diversity of 23 ' $\mathrm{Ca}$. L. asiaticus' isolates with different symptoms from seven provinces in China (69). The study revealed that different isolates were distributed in three subgroups depending on their geographical origins, and no genetic evidence for host determination was observed. The alignments in a $1.5-\mathrm{kb}$ region of the rpoB of the ' $\mathrm{Ca}$. L. asiaticus' and ' $\mathrm{Ca}$. L. africanus' strains revealed that the strain from China differed by two single-nucleotide polymorphisms (SNPs) from the Japan, Florida, and Brazil strains, which were identical at this locus (38). In many Japanese and several South Asian isolates, including those from Taiwan, Indonesia, the Philippines, Vietnam, and Thailand, the 16S rDNA genes are identical $(126,130)$. However, numerous SNPs have been reported in many Chinese isolates and two Indian isolates collected from southwest India (2). Phylogenetic analysis with 16S rDNA sequences and SNPs of the omp gene region revealed that the northeastern Indian isolates were genetically closer to common Asian isolates from Japan, Taiwan, and Vietnam than to the Indian isolates reported previously from western parts of India (104). This result showed that the Asian-common strains of ' $\mathrm{Ca}$. L. asiaticus', as well as the other diverse atypical strains, are distributed in India. On the basis of the 11 nucleotide substitutions in the 11,168-nucleotide sequence of the serA-trmU-tufB-secE-nusG-rplKAJL-rpoB gene cluster and its flanking region, Furuya et al. (53) showed that one unique genetic group is dominant around the Okinawa Main Island of Japan, whereas several different isolates were found to be frequently distributed around islands near Taiwan. Tomimura et al. (130) applied duplex PCR that can simultaneously amplify the DNA pol and nus-rplL operon in 65 ' $\mathrm{Ca}$. L. asiaticus' isolates and reported that Japanese ' $\mathrm{Ca}$. L. asiaticus' isolates contain at least two distinct genotypes, and the genotype that had the DNA pol is highly homogeneous. Katoh et al. $(79,80)$ identified 27 simple single repeats (SSRs) with 4 to 63 nucleotides per unit in the genome of the ' $\mathrm{Ca}$. L. asiaticus' psy 62 strain. A dendogram analysis of diversity within these 27 SSR loci among ' $C a$. L. asiaticus' isolates from India, East Timor, Papua New Guinea, and Florida showed that the clusters were mostly consistent with the geographical origin of the isolates $(79,80)$. Furthermore, the differences in the nucleotide sequences were not associated with the differences in the citrus host from which the isolates were originally derived. Recently, a genomic region (CLIBASIA_05640 to CLIBASIA_05650) of ' $\mathrm{Ca}$. L. asiaticus' showing hypervariability was identified and investigated using 262 bacterial strains (188 from China and 74 from Florida) (149). Based on the characteristic electrophoretic profiles of the PCR amplicons generated by a specific primer set, eight electrophoretic types (E-types) were identified. Strains from China predominantly consisted of E-types A and B, whereas E-type $\mathrm{G}$ was predominant in Florida.

Chen et al. (26) identified the bacteriophage repressor protein $\mathrm{C} 1$ as a genetic marker containing small tandem repeats in the genome of ' $\mathrm{Ca}$. L. asiaticus' and comprehensively analyzed the tandem repeat numbers (TRNs) in ' $C a$. L. asiaticus' populations from Guangdong, China and Florida. An analysis of TRNs showed that the bacterial population in Guangdong consisted predominantly of strains with a TRN of 7 and was different from that in Florida, where most of the isolates had a TRN of 5. Moreover, two TRN subgroups, one widely distributed throughout Florida and the other limited to central Florida, were identified. Zhou et al. (157) described the genetic diversity of ' $\mathrm{Ca}$. L. asiaticus' by using hypervariable prophage genes with intragenic tandem repeats. Sequence conservation within the individual repeats but an extensive variation in the repeat numbers, rearrangement, and the sequence flanking the repeat region indicated the diversity and plasticity of the ' $\mathrm{Ca}$. L. asiaticus' bacterial populations in the world. These differences were found not only in samples of distinct geographical origins but also in samples from a single origin and even from a single ' $\mathrm{Ca}$. L. asiaticus'-infected sample. An analysis of a prophage terminase gene revealed genetic variations in the populations of two citrus-growing provinces in China (94). Differences between the two sets of populations were postulated to be the result of evolutionary genetic drift due to their geographical separation over an estimated period of 30 to 40 years.

\section{HOST RANGE}

When discussing hosts in HLB, two types of plants are of concern: the plant that supports the psyllid vectors and the plant in which the bacterial pathogen can multiply. Research shows that the two types of plants have different significance in HLB management. Compared with the wide physiological host range of the bacterial pathogens, the psyllid vectors have a relatively narrow host range. Considering the low vector-pathogen specificity, this may have potential implications for the disease epidemiology $(61,65)$.

Host of vector. Halbert and Manjunath (65) have provided lists of plant species that are hosts to $\mathrm{D}$. citri and ' $\mathrm{Ca}$. Liberibacter' spp. Because many of the hosts on the two lists were included 
based on field surveys (i.e., observations of plant symptoms or psyllid behavior) and only a few have been verified by PCR tests, the host status of various plants has not been experimentally established. Psyllids can feed on many citrus species and close relatives of citrus but the preferred hosts are Murraya paniculata (Orange jasmine and mock orange) (11) and Citrus aurantifolia (65). Tsai and Liu (139) found that the grapefruit was the best host of $D$. citri out of the four plants studied: M. paniculata (L.) Jack (orange jasmine), C. jambhiri Lushington (Rough lemon), $C$. aurantium L. (sour orange), and Citrus $\times$ paradisi Macfad. (grapefruit); there was no significant difference among the other three hosts. Continuous shoot growth of $M$. paniculata plays an important role in maintaining ACP populations when citrus flush is not available (140). Based on greenhouse studies, Halbert and Manjunath (65) suggested that the two Florida native Zanthoxylum plants, Zanthoxylum clavahercules L. and Z. fagara (L.) Sarg., and Casimiroa edulis Llave \& Lex. may be non-hosts (or very poor hosts, as in the case of Z. fagara) of the ACP. In line with these greenhouse observations, the authors also reported that no ACPs were found on Z. fagara plants growing next to an infested lime grove in South Florida (65).

Citrus hosts. The available information on the host range of the Liberibacter is based primarily on symptoms (65). Most citrus cultivars, especially commercial ones, are susceptible to some degree, regardless of their rootstock $(20,65)$. However, one characteristic of HLB is that different degrees of disease and symptoms are induced in different types of citrus. Furthermore, different isolates of ' $\mathrm{Ca}$. L. asiaticus' can cause varying degrees of disease in citrus cultivars (137). The most severe symptoms are found on sweet orange, mandarin, tangelo, and grapefruit, followed by lemon, rough lemon, and sour orange $(20,65,83$, 94,138). Small-fruited acid lime trees (Citrus aurantifolia) are only slightly affected but clear-cut blotchy mottle symptoms can be observed on leaves.

There is no real resistance to HLB in citrus species but some species and cultivars have some tolerance. Several extensive field surveys have demonstrated that some cultivars were more susceptible to decline than others (83). For example, grapefruit was more tolerant than most of the sweet orange cultivars. Some citrus species ( $C$. indica Tan. and $C$. macroptera Montr.) remained symptom-free under heavy inoculum pressure (18), which may indicate a certain degree of resistance. In Taiwan, severe leaf yellowing was first noticed in 'Ponkan' mandarin, 'Tankan' tangor, and 'Liucheng' sweet orange but not in 'Wentan' pummelo in the field in 1951 (101). The pummelo cultivar that was formerly resistant to HLB eventually became infected and displayed HLB symptoms $\approx 30$ years after HLB first appeared (70, 125). The kumquat (Fortunella margarita (Lour.) Swingle), which was formerly resistant to HLB, recently became infected and displayed yellow mottling symptoms in 2006 (138). It was assumed that the change in host range was due to the evolution of HLB strains in pathogenicity. Most of the information on different citrus genotype reactions to HLB has been accumulated from observations of field trees made under different conditions, at different geographic locations and at different times which limits our ability to make conclusions on the resistance of different citrus cultivars against HLB.

Various studies have also reported that several citrus relatives, such as Severinia buxifolia (Poiret) Ten. (34,72,73,115), Limonia acidissima L. (72,83), Clausena lansium $(35,37)$, and Toddalia lanceolata Lam (85), could harbor HLB-associated bacteria.

Alternative hosts. Field observation and laboratory studies have confirmed that $M$. paniculata is a preferred ACP host; however, its alternative host status for HLB-associated bacteria is not yet clear $(72,96,148)$. Hung et al. (72) used a graft inoculation technique to demonstrate that ' $\mathrm{Ca}$. L. asiaticus' can replicate in the Chinese box orange (S. buxifolia) and the wood apple
(L. acidissima) but not in the common jasmine orange ( $M$. paniculata) or the curry leaf (i). On the contrary, Halbert and Manjunath (65) have found consistent symptoms in inoculated $M$. paniculata plants. $M$. paniculata shows leaf yellowing, defoliation, and dieback on branches when infected with ' $\mathrm{Ca}$. L. asiaticus' or ' $C a$. L. americanus' in Brazil $(95,96)$. Zhou et al. (158) also found $M$. paniculata to be naturally infected with ' $\mathrm{Ca}$. L. asiaticus' in Florida. Zhou et al. (158) concluded that $M$. paniculata can serve as an infection source for ' $\mathrm{Ca}$. L. asiaticus' because it can host ' $C a$. L. asiaticus' for at least 2 months, and ' $C a$. L. asiaticus' can be transmitted to the sweet orange during this time. Controlled inoculation experiments with two isolates of 'Ca. L. asiaticus' using D. citri as vector showed that $M$. paniculata is variable as a reservoir host of the HLB-associated pathogen (33). Because the bacterial population in M. paniculata becomes extremely low after 5 months, $M$. paniculata (as well as another Murraya sp., M. exotica) could only serve as a bridging host if citrus are present during that period of time. Field surveys conducted in Florida and Brazil found an extremely low incidence of ' $C a$. L. asiaticus' in ornamental M. paniculata and associated psyllids (D. citri) $(96,148)$. However, the importance of $M$. paniculata in HLB disease epidemics should not be underestimated, because it is a preferred host of ACP and is not being subjected to any strict tree-eradication programs or insect control measures. In the Western Cape Province of South Africa, Calodendron capense, an ornamental rutaceous tree (Cape chestnut tree), showed blotchy mottle leaves and was found to be infected with a Liberibacter. The new Liberibacter was characterized as subspecies "capensis" of ' $C a$. L. africanus' (57).

Non-Rutaceous hosts. Some hosts outside the Rutaceae family can be experimentally inoculated with ' $\mathrm{Ca}$. Liberibacter' spp., and they are used in various HLB studies. It has been demonstrated that all three citrus Liberibacters can be transmitted to periwinkle plants by dodder (Cuscuta spp., in the Cuscutaceae family) (56). Dodder can be effectively colonized by ' $\mathrm{Ca}$. L. asiaticus' and ' $\mathrm{Ca}$. L. americanus', and the bacteria can multiply internally to a high level. The bacteria are unevenly distributed in dodder as in citrus (66). Dodder can be used to transmit HLB-associated pathogens to citrus $(154,156)$, non-Rutaceous plants such as periwinkle (Catharanthus roseus L. G. Don, in the Apocynaceae family) $(56,66,155)$ and several solanaceous plants such as tomato (41) and tobacco (Nicotiana tobacum L. 'Xanthii') (56), which indicates that ' $\mathrm{Ca}$. L. asiaticus' has a wide physiological host range. Fan et al. (46) reported that the non-Rutaceae plant Pithecellobium lucidum Benth showed yellow shoots, mimicking the symptom of HLB, in a citrus orchard in Fujian, China, where citrus plants were severely infected by HLB. The results of a low ' $\mathrm{Ca}$. L. asiaticus' bacterial titer and the lack of psyllid propagation in this host plant indicated that the new host is an opportunistic host of HLB.

\section{GENOME ANALYSIS}

Despite the difficulty in acquiring pure genomic DNA, ' $C a$. L. asiaticus' has been sequenced successfully, which provides a basis for the assessment of the metabolic and functional capabilities of the pathogen. Genomic analysis of ' $\mathrm{Ca}$. L. asiaticus' has provided useful insights into the biology and pathogenicity of the HLB pathogen (40). Here, we emphasize two main aspects of the metabolic capacity related to the central carbohydrate metabolism and respiration of ' $\mathrm{Ca}$. L. asiaticus' and offer a perspective that is slightly different than a previous analysis (40).

Central carbohydrate metabolism. ' $\mathrm{Ca}$. L. asiaticus' is able to metabolize a very limited set of sugars, including glucose, as a carbon and energy source. The genome sequence provides evidence for a near complete set of glycolytic enzymes, with the possible exception of glucose-6-phosphate isomerase, though this 
gene may be an example of nonorthologous gene displacement. ' $C a$. L. asiaticus' lacks a glucose phosphotranferase system. Glucose is most likely imported into the cell via a glucose/galactose transporter, which is present in ' $\mathrm{Ca}$. L. asiaticus'. Thus, ' $\mathrm{Ca}$. L. asiaticus' is likely able to utilize glucose as a carbon and energy source.

The ' $C a$. L. asiaticus' genome encodes a full inventory of enzymes necessary for the tricarboxylic acid (TCA) cycle. The conversion of glucose and TCA intermediates to pyruvate provides the majority of pyruvate in the cell because enzymes for the direct formation of pyruvate, such as serine dehydratase, alanine racemase, and alanine dehydrogenase, are not present in the genome. The lack of a glyoxylate bypass indicates that isocitrate lyase and malate synthase are also absent from the genome, suggesting that the bacterium is incapable of growth on acetate or fatty acids. This information indicates that ' $C a$. L. asiaticus' uses exogeneous fumarate, malate, succinate, and Laspartate as carbon substrates for the TCA cycle and pyruvate generation as energy sources. This conclusion is supported by the fact that a $\mathrm{C} 4$ dicarboxylate transport protein has been identified in the ' $C a$. L. asiaticus' genome. The import of L-aspartate is facilitated by the existence of an ABC-type L-amino acid transport cassette comprising substrate-binding, permease, and ATPbinding components.

Respiratory chain. ' $\mathrm{Ca}$. L. asiaticus' has a respiratory chain capable of transferring electrons from reduced substrates to oxygen under microaerophilic growth conditions. It appears that malate, fumarate, succinate, aspartate, and glutamate can be used as carbon sources by this organism, because enzymes that utilize these compounds are encoded in the genome. A malate dehydrogenase that would allow the oxidation of malate to oxaloacetate and, thus, feeds into the TCA cycle is present. The reducing equivalents generated are transferred down to an exogeneously derived quinone pool. An important component of the ' $C a$. L. asiaticus' aerobic respiratory chain identified in the genome is the NADH dehydrogenase complex. It appears that the reduced genome of this phytopathogen is devoid of genes for the biosynthesis of menaquinone and ubiquinone. Thus, for a functional respiratory chain, exogenous quinone needs to be used.

The absence of nitrate, sulfate, fumarate, and trimethylamine reductase systems suggests that ' $C a$. L. asiaticus' does not have an anaerobic respiratory scheme. Duan et al. (40) suggested that anaerobic respiration by ' $C a$. L. asiaticus' occurs, based on the observation of enzymes involved in nitrogen metabolism such as $\mathrm{NAD}^{+}$synthase, glutamine synthetase, and glutaminase. However, there is a clear distinction between the enzymes involved in nitrogen metabolism and electron acceptors for an anaerobic respiratory chain. The functions of the enzymes identified in nitrogen metabolism (e.g., $\mathrm{NAD}^{+}$synthase, glutamine synthetase, and glutaminase) do not define a respiratory chain. We did not find evidence of any electron acceptors for anaerobic respiration using nitrogen, specifically nitrate or nitrite reductases. In the absence of these acceptors, it is difficult to have a respiratory chain coupled to the reduction of nitrogen compounds. In addition, both Spiroplasma citri and Serratia marcescens could infect phloem, and both are facultative anaerobe bacteria that make ATP by aerobic respiration when oxygen is present $(1,151)$. This is further supported by the culture condition of L. crescens in the presence of oxygen (89). It is important to note that oxygen is present in the phloem. In a previous study of Ricinus communis, oxygen levels in phloem were shown to range from $21 \%$ (vol $/ \mathrm{vol}$ ) at the surface to $7 \%(\mathrm{vol} / \mathrm{vol})$ in the vascular region and $15 \%$ ( $\mathrm{vol} / \mathrm{vol})$ toward the hollow center of the stem, compared with $21 \%$ (vol/vol) oxygen in air (145). Thus, phloem can support aerobic respiration of ' $\mathrm{Ca}$. L. asiaticus' even though the oxygen level in the phloem is lower than atmospheric levels.

\section{‘CA. L. ASIATICUS' TRANSMISSION}

' $C a$. L. asiaticus' may spread locally and regionally via citrus psyllids and can be disseminated by the propagation of contaminated scion budwood by grafting (66). Grafting is a common practice in citrus production that maintains the horticultural characteristics of a scion. Preventing HLB transmission via grafting has been taken into consideration in management and regulation and is easily achievable. Grafting transmission was recently reviewed by Halbert and Manjunath (65), and the reader is referred to that excellent review. Psyllid transmission is the dominant factor in the epidemiology of HLB, and stopping psyllid transmission has been the major focus of the citrus industry despite the extreme difficulty of preventing psyllid transmission of ' $C a$. L. asiaticus'. Tremendous efforts have been made in recent years to understand the mechanism of the psyllid transmission of ' $\mathrm{Ca}$. L. asiaticus', with the aim of designing innovative management strategies to combat HLB. In addition, seed transmission has been a concern because the rootstocks used to produce trees are grown locally from seed. Therefore, we will mainly discuss psyllid transmission and will briefly discuss seed transmission of ' $\mathrm{Ca}$. L. asiaticus'.

Psyllid transmission of ' $\boldsymbol{C a}$. L. asiaticus'. ' $\mathrm{Ca}$. Liberibacter' spp. are naturally transmitted by two vectors: the ACP D. citri (Kuwayama [Hemiptera: Sternorrhyncha: Psyllidae]) and the African psyllid Trioza erytreae (del Guercio) (Hemiptera: Sternorrhyncha: Triozidae). D. citri is responsible for the transmission of ' $\mathrm{Ca}$. L. asiaticus' in Asia and the Americas and ' $\mathrm{Ca}$. L. americanus' in Brazil. T. erytreae is responsible for the transmission of ' $C a$. L. africanus' in the Middle East, Mauritius, Reunion, and Africa $(9,65)$. It was demonstrated that $T$. erytreae is able to transmit 'Ca. L. asiaticus' under experimental conditions (100).

A psyllid can acquire the pathogen during the nymphal and adult stages $(24,74,114,153)$. Acquisition by nymphs was 60 to $100 \%$, whereas acquisition by adults reached $40 \%$ after 5 weeks of feeding on ' $\mathrm{Ca}$. L. asiaticus'-infected plants under laboratory conditions (114). Similar results were observed under field conditions (114). It was reported that the ACP can acquire ' $\mathrm{Ca}$. L. asiaticus' in a minimum of $15 \mathrm{~min}$ to $24 \mathrm{~h}(22,24)$. However, PelzStelinski et al. (114) indicated that adult psyllids were unable to acquire ' $\mathrm{Ca}$. L. asiaticus' in the first week of pathogen exposure. The acquisition rate of ' $\mathrm{Ca}$. L. asiaticus' by the adult ACP was positively affected by prolonged feeding $(24,114)$. The latent period required for ' $\mathrm{Ca}$. L. asiaticus' to incubate inside the psyllid following acquisition before it can be transmitted can vary from 1 (153) to 8 days post-acquisition (23).

' $\mathrm{Ca}$. L. asiaticus' has been reported to be transmitted by ACP in a persistent manner $(24,74,153)$. Psyllids were reported to maintain ' $\mathrm{Ca}$. L. asiaticus' for 12 weeks (71), which covers most of the $\approx 90$-day lifespan of psyllids (93). It has also been shown that an infected adult retains its infectivity throughout the adult stage (153). In addition, ' $\mathrm{Ca}$. L. asiaticus' has been reported to invade various psyllid organs and tissues. A transmission electron microscopy study indicated that ' $\mathrm{Ca}$. L. asiaticus' could invade cells of the salivary gland, the filtration chamber of the foregut, and the cells of the midgut and hindgut (153). This observation was further validated by quantitative real-time PCR (QPCR) and fluorescence in situ hybridization (FISH) analyses $(7,8)$. QPCR indicated that ' $\mathrm{Ca}$. L. asiaticus' was present in the salivary glands, the alimentary canal, and the rest of the insect body. FISH analysis indicated that ' $C a$. L. asiaticus' was detected in the filter chamber, midgut, Malpighian tubules, haemolymph, salivary glands, ovaries, and muscle and fat tissues of psyllids.

Multiple studies have suggested that ' $\mathrm{Ca}$. L. asiaticus' is propagative in psyllids. Based on QPCR analysis, the mean concentration of ' $\mathrm{Ca}$. L. asiaticus' increased over time in psyllid after acquisition feeding by fifth instars (74). Ammar et al. $(6,7)$ also 
reported that, in both field- and laboratory-infected $D$. citri, the proportion of infected salivary glands was significantly lower than the alimentary canal and the rest of the insect body. However, the copy number of the ' $\mathrm{Ca}$. L. asiaticus' genome relative to psyllid genomic DNA was significantly higher in both the salivary gland and alimentary canal compared with the rest of the insect body for both male and female psyllids. The distribution pattern of ' $\mathrm{Ca}$. L. asiaticus' is similar to other propagative plant-pathogenic bacteria that are known to multiply in their hemipteran insect hosts (e.g., phytoplasmas, Spiroplasma kunkelii, and S. citri) $(6,21,49)$. Collectively, previous studies seem to suggest that ' $\mathrm{Ca}$. L. asiaticus' replicates in psyllids. However, it has also been reported that the retention of ' $\mathrm{Ca}$. L. asiaticus' in adult psyllids that acquired the pathogen as nymphs decreased over time, which suggests that ' $C a$. L. asiaticus' does not persist in D. citri (114). Considering that most experiments conducted thus far are not comprehensive (because they rely on either symptoms, PCR, or FISH analysis), the combining of multiple approaches to conduct a more comprehensive study of this subject is desirable.

Overall, two different models exist regarding the psyllid transmission of ' $\mathrm{Ca}$. L. asiaticus' to plants. One model is based mainly on studies by Capoor et al. (24) and Xu et al. (153). In both studies, the transmission assays were conducted using indicator citrus plants. Their model suggests that the fourth to fifth instar nymphs and adults can acquire ' $\mathrm{Ca}$. L. asiaticus' and transmit the pathogen to the plant. The emerged adults that fed on infected plants as nymphs could transmit the pathogen in a shorter latent period than could psyllids that fed on infected plants only as adults.

Another model is mainly based on the study by Inoue et al. (74) and Pelz-Stelinski et al. (114). Inoue et al. (74) suggested that the multiplication of ' $C a$. L. asiaticus' in psyllids is essential for efficient transmission and that it is difficult for adults to transmit the pathogen unless they acquire ' $\mathrm{Ca}$. L. asiaticus' as nymphs. Pelz-Stelinski et al. (114) showed that acquisition by only adult psyllids did not result in ' $C a$. L. asiaticus'-infected plants after more than 1 year of incubation after inoculation. Both models suggest that psyllids could acquire ' $\mathrm{Ca}$. L. asiaticus' as nymphs and adults but they disagree on the role of acquisition of ' $\mathrm{Ca}$. L. asiaticus' by only adults in ' $\mathrm{Ca}$. L. asiaticus' transmission. Inoue et al. (74) reported that, when psyllids fed on infected plants as adults, the percentage of ' $\mathrm{Ca}$. L. asiaticus'-positive psyllids declined continuously after an acquisition access period of $24 \mathrm{~h}$, and the concentration of ' $\mathrm{Ca}$. L. asiaticus' did not increase significantly over time in ' $\mathrm{Ca}$. L. asiaticus'. Furthermore, ' $\mathrm{Ca}$. L. asiaticus' was not transmitted to plants and did not cause HLB disease. However, the concentration of ' $\mathrm{Ca}$. L. asiaticus' significantly increased over time after acquisition feeding by fifth instars. It was also reported that acquisition by nymphs was 60 to $100 \%$, whereas acquisition by adults only reached $40 \%$ after 5 weeks of feeding on 'Ca. L. asiaticus'-infected plants (114). Inoue et al. (74) suggested that multiplication within psyllids is required for efficient transmission and that it is difficult for adults to transmit the pathogen unless they acquire the pathogen as nymphs.

The transmission of ' $\mathrm{Ca}$. L. asiaticus' from parent to offspring (transovarial) occurs at a rate of 2 to $6 \%$ (114). ' $\mathrm{Ca}$. L. asiaticus' has been detected in ' $\mathrm{Ca}$. L. asiaticus'-negative female genitalia and, later, in their offspring after mating with a ' $\mathrm{Ca}$. L. asiaticus'infected male (98). This finding is consistent with the occasional detection of ' $\mathrm{Ca}$. L. asiaticus' in psyllid ovaries (8). However, it has also been reported that transovarial passage of ' $\mathrm{C} a$. L. asiaticus' by $D$. citri does not occur $(144,153)$.

Seed transmission. Although ' $\mathrm{C} a$. L. asiaticus' is located in the seed coat (127), it appears not to be seed transmitted $(4,68$, 123). Most data suggest that seedlings do not develop symptoms typical of HLB from HLB-infected seed and that ' $\mathrm{Ca}$. L. asiaticus' is not present in the seedlings germinated from HLB-affected seed $(4,68,123)$. Hilf (68) reported the presence of ' $\mathrm{Ca}$. L. asiaticus' in $10 \%$ of 'Sanguenelli' sweet orange seedlings but not in 'Conners' grapefruit seedlings generated from infected seed. Additionally, ' $\mathrm{Ca}$. L. asiaticus' was not detected in 'Ridge Pineapple' tissue at 3 months post-grafting onto the abovementioned Sanguenelli seedlings. Thus, it does not appear that seed transmission occurs or plays a significant role in ' $\mathrm{Ca}$. L. asiaticus' transmission.

\section{VIRULENCE MECHANISM}

Understanding the citrus-' $C a$. L. asiaticus' interaction and the virulence mechanism of the pathogen is critical to designing innovative management strategies to control HLB. However, due to the difficulty in culturing ' $C a$. L. asiaticus', our understanding of its virulence mechanism is very limited, despite some promising progress.

Phloem blockage and aberrations. Phloem blockage has been suggested to be a major reason for HLB disease symptom development $(81,120)$. HLB-associated phloem blockage results from plugged sieve pores rather than HLB bacterial aggregates because ' $\mathrm{C} a$. L. asiaticus' does not form aggregates in citrus (81). Given the size of ' $\mathrm{Ca}$. L. asiaticus', $\approx 2 \mu \mathrm{m}$ in length and 0.1 to 0.2 $\mu \mathrm{m}$ in diameter (20) or 0.33 to $0.66 \mu \mathrm{m}$ in diameter and 2.6 to 6.3 $\mu \mathrm{m}$ in length (66), it is unlikely that a single HLB bacterium could plug the sieve pores, which range from $<1 \mu \mathrm{m}$ to $\approx 14 \mu \mathrm{m}$ (44). Phloem blockage is partially due to the deposits of large amounts of callose, as confirmed by staining with aniline blue. Phloem proteins might also be involved in phloem blockage because the PP2 gene was induced in HLB diseased citrus compared with the healthy control (81). However, PP2 has been suggested to be a defense response of the host to restrict further spread of the pathogen within the sieve tubes. Analysis of recovered apple from apple proliferation disease has indicated that callose accumulation and phloem-protein deposition in the sieve elements might contribute to the recovery of the infected plant by forming physical barriers, preventing the movement of ' $\mathrm{Ca}$. Phytoplasma mali' from the roots and recolonization of the crown (109). Considering that PP2 genes are not induced in the early stage of infection at 5 to 9 weeks after graft inoculation (3), the phloem protein does not appear to play a critical role in plant defense against ' $\mathrm{Ca}$. $\mathrm{L}$. asiaticus'. Instead, the plugging of the sieve elements might block phloem transportation, leading to nutrient depletion of neighboring cells.

Callose deposition in the sieve plates has also been observed by Koh et al. (82). Additionally, Koh and colleagues observed callose accumulation around plasmodesmata pore units (PPUs) connecting companion cells and sieve elements. It was suggested that callose accumulated around PPUs before starch began to accumulate in the chloroplasts. This suggestion was based on the observation that PPUs in the ' $C a$. L. asiaticus'-infected asymptomatic leaves were stained for callose at levels similar to that of PPUs in the symptomatic leaves. Transmission electron microscopy also indicated that PPUs with abnormally large callose deposits were more abundant in the ' $\mathrm{Ca}$. L. asiaticus'-infected samples than in healthy leaves. Callose formation around PPUs in ' $\mathrm{Ca}$. L. asiaticus'-infected leaves inhibited the symplastic flow of solutes from companion cells into sieve tubes, thereby reducing the phloem loading efficiency based on the monitoring of a symplast fluorescent tracer carboxyfluorescein diacetate (CFDA). In healthy leaves, CFDA is imported into the veins. In contrast, the fluorescence in minor veins is often dimmer than it is in the surrounding nonvascular tissue in ' $\mathrm{Ca}$. L. asiaticus'-infected leaf samples, indicating that CFDA remains in the nonvascular tissue.

This blockage harms not only plant cells but also ' $\mathrm{Ca}$. L. asiaticus'. Therefore, ' $\mathrm{Ca}$. L. asiaticus' might eventually become nonviable in completely blocked sieve elements (133). Interestingly, 
large numbers of ' $C a$. L. asiaticus' cells were found in phloem sieve tubes in tissue samples from presymptomatic young flushes but they were not found in highly symptomatic leaf samples (51).

Sucrose is the primary photoassimilate in phloem transported from mature leaves to sink organs (159). Sucrose accumulation in ' $C a$. L. asiaticus'-infected leaves suggests that photoassimilate translocation is impaired by ' $\mathrm{Ca}$. L . asiaticus' infection, most likely due to phloem blockage $(47,48,81,82)$. Koh et al. (82) carried out $\mathrm{CO}_{2}$ pulse-labeling experiments and determined that ' $C a$. L. asiaticus' infection interferes with photoassimilate export from source leaves. In healthy leaves, $81 \%$ of ${ }^{14} \mathrm{C}$ (measured at time 0) disappeared within $24 \mathrm{~h}$, whereas only $46 \%$ of radioactivity was released from ' $\mathrm{Ca}$. L. asiaticus'-infected leaves. The delayed export of fixed ${ }^{14} \mathrm{C}$ from the ' $\mathrm{Ca}$. L. asiaticus'-infected leaves suggests that the starch buildup in the chloroplasts of ' $\mathrm{Ca}$. L. asiaticus'-infected leaves may have resulted from the delayed translocation of photosynthates. This reduced photoassimilate transportation might contribute to the small, misshapen, and poorly colored fruit containing aborted or partially developed seed. Sucrose deficiency has been associated with fruit growth arrest (59). Importantly, the flavedo from ' $\mathrm{Ca}$. L. asiaticus'infected trees has been reported to have a lower carbohydrate content (116). Additionally, Fan et al. (48) compared the phloem transport activity in the midribs of source leaves of tolerant rough lemon $(C$. jambhiri) and susceptible sweet orange ( $C$. sinensis) in response to ' $\mathrm{Ca}$. L. asiaticus' infection. Their study indicated that, although microscopic changes (e.g., callose deposition in sieve elements and phloem cell collapse) were found in both infected species, the phloem transport activity of rough lemon was much less affected by HLB than in sweet orange.

Starch accumulation has also been reported to be increased in infected aerial tissues but depleted in roots. Interestingly, it has been observed that many genes involved in photosynthesis are repressed, most likely due to increased sucrose/glucose levels, as photosynthesis/chlorophyll-associated genes, such as those encoding the photosystem-II 5-kDa protein, photosystem-I subunit $\mathrm{O}$, and a chlorophyll A-B binding family protein, were downregulated by ' $\mathrm{Ca}$. L. asiaticus' infection $(3,47,81)$. However, bark samples and symptomless leaves also contain higher levels of starch than healthy controls without visible phloem blockage (45). This seems to suggest that other mechanisms in addition to phloem blockage might also be involved in HLB disease development.

Other microscopic aberrations have been observed in the ' $\mathrm{Ca}$. L. asiaticus'-infected Madam Vinous sweet orange seedlings (51), including swelling of the middle lamella between cell walls surrounding the sieve elements. The development of HLB symptoms correlated with an increasing degree of microscopic aberrations. Interestingly, large numbers of ' $\mathrm{Ca}$. L. asiaticus' cells were observed in tissue samples from asymptomatic young flushes but not in highly symptomatic leaf samples (51). In addition, microscopic studies of leaf samples from symptomatic sweet orange field trees demonstrated necrosis in the phloem, massive accumulation of starch in the plastids, aberrations in cambial activity, and excessive phloem formation and phloem collapse $(81,119)$. It was suggested that extensive phloem necrosis contributes to the blockage of the phloem transportation, which leads to other anatomical changes. Consequently, these changes are responsible for the blotchy mottle, yellowing, leatheriness, and vein clearing on the leaves of infected trees (119).

Metabolic imbalances by nutrient depletion. Duan et al. (40) suggested that ' $\mathrm{Ca}$. L. asiaticus' is parasitic rather than pathogenic, causing host metabolic imbalances by nutrient depletion or interference with transportation, which results in HLB symptoms.

Knowledge of the carbon source and sugar metabolism of ' $\mathrm{Ca}$. L. asiaticus' facilitates understanding of its pathogenicity. ' $\mathrm{Ca}$. L. asiaticus' may disrupt host cellular metabolic functions by im- porting multiple host-cell metabolites for growth and development, ultimately leading to disease expression. ' $\mathrm{Ca}$. L. asiaticus' has the ability to metabolize sugars such as glucose, fructose, and xylulose but not mannose, galactose, rhamnose, or cellulose (40). The concentrations of fructose and glucose are very low in the phloem sap $(28,50)$; therefore, consumption of fructose by ' $\mathrm{Ca}$. L. asiaticus' during infection may initiate a shift in the host metabolite distribution. Fan et al. (47) observed a remarkable accumulation of glucose but not fructose and suggested that ' $\mathrm{Ca}$. L. asiaticus' might preferentially utilize fructose, similar to $\mathrm{S}$. citri. Thus, ' $C a$. L. asiaticus' infection will result in reduced fructose concentrations and the accumulation of glucose in the infected host tissues. Glucose accumulation will subsequently favor the repression of enzymes involved in photosynthesis and contribute to HLB symptom development. Interestingly, the consumption of fructose by $S$. citri has been implicated in affecting phloem loading of sucrose, sugar accumulation in source leaves, and causing disease symptoms, including yellowing. Sugar and starch accumulations have been observed previously in citrus trees infected by ' $C a$. Liberibacter' spp. $(81,119)$. It is possible that ' $C a$. L. asiaticus' could affect the phloem loading of sucrose in citrus and result in starch accumulation. Such mechanisms of pathogenicity are based not on specific genes, such as genes for toxins, but on deviations in sugar metabolism. However, ' $\mathrm{Ca}$. L. asiaticus' encodes only one sugar transporter for glucose/galactose (40). It is unknown how ' $\mathrm{Ca}$. L. asiaticus' imports fructose from its host. Thus, this hypothesis needs further validation.

' $C a$. L. asiaticus' encodes a relatively low number of genes involved in the biosynthesis of compounds, which are readily taken up from the host. Analysis of the de novo amino acid biosynthetic pathways of ' $\mathrm{Ca}$. L. asiaticus' has revealed that they are capable of producing serine, glycine, cysteine, aspartate, lysine, threonine, glutamate, and arginine and incapable of making histidine, tyrosine, thiamine, phenylalanine, tryptophan, asparagine, isoleucine, methionine, alanine, valine, leucine, and proline. Interestingly, the culturable nature of $L$. crescens is postulated to be due, in part, to the presence of genes involved in the synthesis of essential amino acids phenylalanine and tyrosine (89). The deficiencies in amino acid biosynthesis can be countered by the bacterium through the import of exogeneous amino acids. Accordingly, the ' $C a$. L. asiaticus' genome encodes a set of general L-amino acid permease proteins that are able to transport a variety of amino acids into the cell. In addition, a gene encoding a branched-chain proton-glutamate transporter that is able to import both glutamate and aspartate is present in the genome. Also, ' $\mathrm{Ca}$. L. asiaticus' possess a thiamine ABC transporter not found in $L$. crescens, presumably to compensate for the inability to synthesize thiamine (89).

' $C a$. L. asiaticus' encodes 137 transporter proteins with 92 genes that are involved in active transport, including $40 \mathrm{ABC}$ transport genes. Recently, Li et al. (90) analyzed all of the ABC transporter-related proteins in ' $\mathrm{Ca}$. L. asiaticus' and identified 14 $\mathrm{ABC}$ transporter systems and 7 nontransporting $\mathrm{ABC}$ proteins. The study showed that the bacterium could use these ABC transporters to import metabolites (amino acid and phosphates) and enzyme cofactors (choline, thiamine, iron, manganese, and zinc); resist organic solvent, heavy metal, and lipid-like drugs; maintain the composition of the outer membrane; and secrete virulence factors. The large number of transporter proteins might play a critical role in providing ' $\mathrm{Ca}$. L. asiaticus' with necessary nutrients and cause a metabolic imbalance in citrus. Interestingly, ' $\mathrm{Ca}$. L. asiaticus' encodes one zinc transport system (znuABC) (40). Vahling-Armstrong et al. (143) demonstrated that the $z n u A B C$ system of ' $\mathrm{Ca}$. L. asiaticus' is functional and is responsible for high-affinity zinc uptake. Therefore, this system might contribute to the zinc deficiency associated with HLB-affected trees. A comparison of the znuABC homologues of Sinorhizobium meliloti and 
' $C a$. L. asiaticus' also revealed the existence of distinct modes of regulation between the zinc import systems, despite the intracellular-plant niche that is common to both bacteria (143). Although zinc $\mathrm{ABC}$ transporters are also present in L. crescens, they show very low sequence similarity with ' $\mathrm{Ca}$. L. asiaticus' (89). This variation in zinc $\mathrm{ABC}$ transport proteins may contribute to the differences in the virulence of the Liberibacter genus. A twin arginine translocation protein export pathway and an additional iron $\mathrm{ABC}$ transporter are present in L. crescens but not in 'Ca. L. asiaticus' (89). The significance of these two transporters is not currently known but their existence may explain why L. crescens is less fastidious than ' $\mathrm{Ca}$. L. asiaticus'.

' $C a$. L. asiaticus' also encodes an ATP/ADP translocase in addition to its ATP synthase so that it can utilize the energy source directly from its host, as do other obligate intercellular parasites such as Rickettsia prowazeki $(40,142,152)$.

Hormone. Phytohormones have been known to influence citrus fruit set, productivity, and plant response to plant pathogen infection (116). Rosales and Burns (116) compared the phytohormones in symptomatic fruit (S), asymptomatic fruit (AS) from symptomatic trees, and healthy fruit $(\mathrm{H})$ from asymptomatic trees harvested from Valencia sweet orange trees (C. sinensis (L.) Osbeck). It was shown that $\mathrm{S}$ and $\mathrm{AS}$ harvested 7 and 12 months after full bloom produced significantly less ethylene than $\mathrm{H}$. The indole-3-acetic acid (IAA) and abscisic acid (ABA) contents in flavedo from the stylar end, middle section, or stem end of fruit were higher in $\mathrm{S}$ flavedo than in AS and $\mathrm{H}$. Although ethylene promotes abscission, the ethylene-IAA balance is known to play a regulating role in controlling fruit abscission (121). The fourfold lower IAA content in the stem end of $\mathrm{S}$ is suggested to accelerate abscission, although ethylene production in the whole fruit is lower. The IAA content was higher in the misshapen region compared with the normal-growing areas of S. The hypodermal cell size was also increased in the corresponding regions. Therefore, IAA has been suggested to play a role in the development of misshapen fruit areas (116).

Suppression or avoidance of plant defense. Unsuccessful attempts to culture ' $\mathrm{Ca}$. L. asiaticus' have slowed the dissection of molecular mechanisms of pathogenesis and the avoidance or suppression of plant innate immunity. It has been suggested that ' $C a$. L. asiaticus' elicits a delayed defense response (81). How ' $C a$. L. asiaticus' manipulates the plant defense response is critical to its survival in planta.

The reduced genome of ' $\mathrm{Ca}$. L. asiaticus' and transmission by psyllids might allow it to avoid pathogen-associated molecular pattern (PAMP)-triggered immunity. Plants use pattern recognition receptors, which are typically localized in the plant cell membrane, to respond to microbial-associated molecular patterns or PAMPs $(77,78)$. Plants recognize a wide range of bacterial PAMPs, most of which are derived from structural components of the bacterial cell (112). PAMPs induce rapid and transient production of reactive oxygen species (ROS) in an oxidative bust following the recognition of a variety of pathogens $(12,39,63$, 112). In addition, ' $C a$. L. asiaticus' lacks type II plant cell-walldegrading enzymes, which have been known to elicit defense responses based on autodegradation products of the plant cell wall (oligogalacturonides) (113). However, ' $\mathrm{Ca}$. L. asiaticus' still contains 57 genes in cell envelope biogenesis; the outer membrane, including lipopolysaccharides; and most flagellar genes (40), which might function as PAMPs. It has been shown that ' $\mathrm{Ca}$. L. asiaticus' contains a functional fla gene encoding a flagellin and hook-associated protein of 452 amino acids that contains the conserved flg22 (160). The fla gene could partially complement the corresponding $S$. meliloti fla mutant. Transient expression in planta indicated that Fla $_{\text {Las }}$ induced cell death and callose deposition in $N$. benthamiana and that the transcription of $B A K 1$ and $S G T 1$, which are associated with plant innate immunity, was upregulated. The synthetic Flg22 $2_{\text {Las }}$ peptide could not induce plant cell death but retained the ability to induce callose deposition (160). The influence of flagellin and Flg22 $2_{\text {Las }}$ on the induction of cell death and callose deposition is similar to that of other known flagellin and Flg22 (111). Thus, it has been suggested that ' $\mathrm{Ca}$. L. asiaticus' flagellin may act as a PAMP and trigger host plant resistance to the HLB bacteria (160). However, flagella have not been observed for ' $\mathrm{Ca}$. L. asiaticus', even though most flagellar genes are present in the genome (40). In addition, FLAGELLINSENSING2 (FLS2) is a transmembrane receptor kinase that binds to bacterial flagellin or flg22 through a physical interaction within the FLS2 extracellular domain $(5,42)$. It is unknown how ' $\mathrm{Ca}$. L. asiaticus' perceives the flagellin or flg22 and other PAMPs because ' $C a$. L. asiaticus' resides in the phloem, an intracellular environment rather than an extracellular environment. Interestingly, several components of a fimbrial low-molecular-weight protein (flp) pilus system encoded by Tad family proteins and involved in tight adherence of the bacteria were present in pathogenic and uncultured $\mathrm{Ca}$. L asiaticus but not in nonpathogenic and culturable L. crescens (89). Diversity of the flp pilus operon is predicted to contribute to variation in virulence among pathogenic species, and further studies are warranted to deduce its role in the pathogenicity of ' $\mathrm{Ca}$. L. asiaticus'.

It is noteworthy that the dissemination of ' $\mathrm{Ca}$. L. asiaticus' relies on its psyllid vector. Therefore, it bypasses the preformed and certain induced plant defenses, such as stomata closure $(64,102)$, that are encountered by free-living bacteria such as Pseudomonas and Xanthomonas spp.

Plants also utilize polymorphic nucleotide-binding (NB) leucinerich repeat (LRR) protein products encoded by most resistance genes to recognize pathogens inside the cell (77). This process is mediated through the direct or indirect reorganization of effectors by NB-LRR, resulting in effector-triggered immunity. ' $C a$. L. asiaticus' does not encode type III or IV secretion systems or their effectors (40). ' $C a$. L. asiaticus' might encode other unidentified effectors that are recognized by the host plant once it is inside the phloem. It has been known that cytoplasmic proteins are able to recognize pathogens. In resistant tomato plants, the cytoplasmic protein kinase Pto in plants carrying the NB-LRR gene Prf recognizes AvrPto and AvrPtoB and leads to effector-triggered immunity (108). However, it is unlikely that the plant defense against ' $\mathrm{Ca}$. L. asiaticus' is enough to suppress the HLB pathogen. Microarray analysis has been used to understand the molecular mechanisms underlying HLB disease development $(3,81,47$, $48,91,99)$. It has been suggested that the infection of citrus with ' $C a$. L. asiaticus' does not lead to a significant induction of defense-related genes in the early stages, $\approx 5$ to 9 weeks after inoculation. The citrus host is unable to suppress the pathogen, resulting in the compatibility of the interaction $(3,81)$.

In addition, ' $\mathrm{Ca}$. L. asiaticus' could further suppress the plant defense. Our preliminary data indicate that ' $\mathrm{Ca}$. L. asiaticus' contains CLIBASIA_00255, which encodes a salicylate hydroxylase that, in turn, converts salicylic acid (SA) into catechol, a product that does not induce resistance (146). CLIBASIA_00255 has been shown to be highly induced in planta compared with in psyllid. SA has been reported to play a central role in plant defenses by mediating defense responses against pathogens in a number of plant species (122). SA is important for basal defense, the hypersensitive response, and systemic acquired resistance (43). Expressing salicylate hydroxylase in plants has been shown to abolish plant defenses by degrading SA. For example, Arabidopsis plants carrying the $n a h G$ gene, which encodes a salicylate hydroxylase, are defective in non-host resistance to Pseudomonas syringae pv. phaseolicola strain 3121 (147). Our preliminary analysis indicates that SA hydroxylase is able to degrade SA using the crude extract of Escherichia coli expressing SA hydroxylase. Our data suggest that the modulation of SA production 
could be one of the mechanisms deployed by ' $\mathrm{Ca}$. L. asiaticus' to evade plant defense responses $(135,136)$. This is consistent with the previous finding that a large number of defense-related genes were downregulated or expressed at very low levels in ' $C a$. L. asiaticus'-infected citrus $(3,81)$.

Prophages SC1 and SC2. It has been reported that ' $\mathrm{Ca}$. L. asiaticus' carries an excision plasmid prophage, $\mathrm{SC} 2$, and a chromosomally integrated prophage, $\mathrm{SC} 1$, that becomes lytic in citrus (156). SC1 and SC2 have been suggested to contribute to the pathogenicity of ' $C a$. L. asiaticus'. SC1 carries suspected lytic cycle genes, and phage particles associated with ' $C a$. L. asiaticus' have been observed in the phloem of infected periwinkle using transmission electron microscopy, although phage particles are not observed in citrus. A lytic burst of ' $\mathrm{Ca}$. L. asiaticus' inside a living phloem cell might trigger a cell death or apoptosis cascade, resulting in the subsequent death of the citrus phloem cell. This seems to explain the difficulty of observing ' $\mathrm{Ca}$. L. asiaticus' in symptomatic citrus leaf midribs $(52,81)$. However, ' $C a$. L. asiaticus' has been be observed in young asymptomatic tissues $(51,52)$. SC1 and SC2 also encode multiple virulence factors that might contribute to the pathogenicity of ' $C a$. L. asiaticus' (156). SC1 and SC2 encode two predicated peroxidases that might defend ' $C a$. L. asiaticus' against ROS, including superoxide radicals, hydrogen peroxide, and hydroxyl radicals. SC1 and SC2 also encode two predicated adhesins, which might be useful in transmission by psyllids (156). However, an analysis of multiple isolates of ' $\mathrm{Ca}$. L. asiaticus' from different geographical locations has indicated that $\mathrm{SC} 1$ and $\mathrm{SC} 2$ are not universally present (B. Schneider, personal communication). Leonard et al. (89) have reported that the culturable $L$. crescens contains two prophages (LC1 and LC2) which are not homologous to each other or to the tandem prophage region in ' $\mathrm{Ca}$. L. asiaticus'. The involvement of $\mathrm{SC} 1$ and SC2 in the pathogenicity of ' $\mathrm{Ca}$. L. asiaticus' needs further characterization.

Serralysin and hemolysin. ' $C a$. L. asiaticus' encodes multiple putative virulence genes, including genes encoding serralysin and hemolysin. Serralysin, a putative type I secretion system (T1SS) effector that is encoded by CLIBASIA_01345 and is located next to the T1SS locus in the genome, was identified using a computational analysis of ' $C a$. L. asiaticus' $(29,40)$. In our recent study, we found that the expression of CLIBASIA_01345 was upregulated in planta compared with in psyllid (154). Serralysin is a secreted metalloprotease produced by a wide range of microorganisms, including plant and human pathogenic bacteria such as Serratia marcescens, Pseudomonas aeruginosa, Erwinia chrysanthemi, Proteus mirabilis, and Caulobacter crecentus $(32,97)$. It has been shown that serralysin inactivates diverse antimicrobial proteins and peptides (118). For example, serralysin produced by $P$. mirabilis was reported to degrade host immunoglobulins and cleave antimicrobial peptides, including human $\beta$-defensin and LL-37 (17). The production of antimicrobial proteins and peptides is one of the major defense strategies utilized by a plant in response to infection by pathogenic organisms (25). The upregulation of the serralysin biosynthesis gene in planta indicates that ' $C a$. L. asiaticus' may also utilize serralysin to modify the plant defenses, possibly by degrading host antimicrobial peptides. It has also been suggested that serralysin might aid in the acquisition of carbon and nitrogen for bacterial growth and metabolism through the proteolysis of host proteins and nutrient uptake $(16,17)$. Serralysin may further help ' $C a$. L. asiaticus' survive in its hosts. In addition, the introduction of exogenous antimicrobial peptides to citrus plants by various transgenic approaches is being used to control HLB. The presence of serralysin poses a potential challenge in the selection of efficient antimicrobial peptides against ' $\mathrm{Ca}$. L. asiaticus'. Thus, the serralysin of ' $\mathrm{Ca}$. L. asiaticus' could be a potential target for screening antimicrobial compounds to control HLB.
Hemolysin produced by animal and insect pathogens is believed to induce cell lysis, necrosis, and apoptosis (89); increase the availability of iron to the pathogen (124); and cause the leakage of ions, water, and low molecular weight molecules out of and into the host cell (62). Hemolysin is present in other plantpathogenic bacteria, including phytoplasmas and Xylella fastidiosa $(13,19)$, and is postulated to play an important role in degrading proteins produced by host cells in the defense reaction or by degrading host proteins for the uptake of essential nutrients (86). Like serralysin, the production of hemolysin by ' $C a$. L. asiaticus' may play an important role in facilitating survival of ' $\mathrm{Ca}$. L. asiaticus' inside the phloem by contributing to nutrient acquisition, ion transfer, and phloem necrosis.

\section{ECOLOGICAL IMPORTANCE OF HLB}

HLB not only directly affects plant production but also affects the agroecosystem. It has been reasonably postulated that the disruption of multitrophic interactions in a stable ecosystem under the influence of a phytopathogen will cause community reorganization and changes in local feedback interactions. However, there is a paucity of knowledge on the extent to which such community shifts may occur, the dynamics of the changes involved, and the putative effects on the functioning of ecosystems. Few studies have used HLB and citrus as disease-host models to evaluate fluctuations in the diversity, composition, structure and functional potential of plant-associated microbial communities in response to disease infection $(117,131,132,134)$.

The profiling of bacterial diversity using various molecularand culture-based methods has shown that HLB infection has a profound effect on the structure and composition of the bacterial community associated with citrus leaves $(117)$, roots $(131,134)$, and rhizospheres (132). Unique phylotypes and genotypes of bacteria have been found to be associated with HLB-infection but apparently not in healthy citrus $(131,134,141)$. Both culture- and molecular-based assessments of bacterial diversity associated with citrus roots showed that the isolation frequency of bacterial isolates possessing various plant-beneficial properties was significantly higher in HLB-asymptomatic samples. The majority of bacterial types in the roots of healthy citrus were similar to known plant-growth-promoting bacteria, including Bacillus, Burkholderia, Caulobacter, Lysobacter, Paenibacillus, Pantoea, and Pseudomonas spp., whereas in planta levels of most of these types of bacteria were reduced in HLB-infected samples $(131,134)$. Representatives of the phylum Actinobacteria, particularly Curtobacterium spp., were detected only in healthy samples $(131,134)$. Taxon-specific QPCR analysis has also revealed that the bacterial community changes not only qualitatively but also quantitatively $(131,132)$. Overall, various reports have shown that the infection of citrus by HLB has a profound effect on the structure and composition of the citrus-associated bacterial community.

Trivedi et al. (132) used QPCR and functional microarray GeoChip 3.0 to evaluate the effect of HLB on the functional diversity of the bacterial community associated with the citrus rhizosphere. Both analyses revealed that HLB has a significant negative effect on the functional diversity of rhizosphere microflora. Many of the genes involved in key ecological processes such as nitrogen, carbon, phosphorus, and sulfur cycling; metal homeostasis and resistance; and xenobiotic contaminant degradation were absent in the rhizosphere of HLB-infected trees. Carbon cycle gene distributions in the rhizosphere of citrus were significantly affected by HLB. The shift in the patterns of rhizodeposition and changes in the carbon utilization and fixation potential of microbial communities in response to HLB can have long-term effects on carbon storage and sequestering. Both GeoChip 3.0 and QPCR analyses revealed that HLB infection leads to a decreased abundance of various genes involved in $\mathrm{N}$ 
cycling, independent of their taxonomic origin. Shifts in the microbial community of these specialist bacteria can have a strong impact on agroecosystem sustainability. According to the insurance hypothesis, species richness has a positive effect on ecosystem productivity through a buffering effect against disturbances. As shown by several studies $(117,131,132,134,141)$, HLB infection can drastically influence the structure and function of citrusassociated bacterial communities, which could potentially have severe consequences for the stability and productivity of ecosystems.

\section{CONCLUDING REMARKS}

With the citrus industry of Florida and possibly that of the entire United States at stake, the need to control HLB and the challenges involved in doing so are unprecedented. However, no "silver bullet" has been identified to control HLB and stop it from spreading to new citrus-production areas, although some promising progress has been made. Further studies are needed to understand the interactions among citrus, ' $\mathrm{Ca}$. L. asiaticus', and psyllids to design innovative management strategies to control HLB. We also presume that the availability of $L$. crescens in culture will greatly speed the hunt for effective treatments against HLB. Although HLB has been a problem for over a century, the battle against HLB can only be resolved with a coordinated and deliberate effort from by the citrus industry, growers, researchers, legislatures, and governments.

\section{ACKNOWLEDGMENTS}

We thank $\mathrm{H}$. Hu for his valuable suggestions regarding the host range of " $\mathrm{Ca}$. L. asiaticus" and its psyllid vector.

\section{LITERATURE CITED}

1. Adams, L., and Boopathy, R. 2005. Isolation and characterization of enteric bacteria from the hindgut of Formosan termite. Bioresour. Technol. 96:1592-1598.

2. Adkar-Purushothama, C. R., Quaglino, F., Casati, P., and Bianco, P. A. 2011. Reverse transcription-duplex-polymerase chain reaction for simultaneous detection of Citrus tristeza virus and 'Candidatus Liberibacter' from citrus plants. J. Plant Dis. Prot. 6:241-243.

3. Albrecht, U., and Bowman, K. D. 2008. Gene expression in Citrus sinensis (L.) Osbeck following infection with the bacterial pathogen 'Candidatus Liberibacter asiaticus' causing huanglongbing in Florida. Plant Sci. 175:291-306.

4. Albrecht, U., and Bowman, K. D. 2009. 'Candidatus Liberibacter asiaticus' and huanglongbing effects on citrus seeds and seedlings. HortScience 44:1967-1973.

5. Ali, G. S., and Reddy, A. S. N. 2008. PAMP-triggered immunity: Early events in the activation of FLAGELLIN SENSITIVE2. Plant Signal. Behav. 3:423-426.

6. Ammar, E.-D., and Hogenhout, S. A. 2006. Mollicutes associated with arthropods and plants. Pages 97-118 in: Insect Symbiosis. B. Kostas and T. Miller, eds. CRC Press, Taylor and Francis Group, Boca Raton, FL.

7. Ammar, E.-D., Shatters, R. G., and Hall, D. G. 2011a. Localization of 'Candidatus Liberibacter asiaticus', associated with citrus huanglongbing disease, in its psyllid vector using fluorescence in situ hybridization. J. Phytopathol. 159:726-734.

8. Ammar, E.-D., Shatters, R. G., Lynch, C., and Hall, D. G. 2011 b. Detection and relative titer of 'Candidatus Liberibacter asiaticus' in the salivary glands and alimentary canal of Diaphorina citri (Hemiptera: Psyllidae) vector of citrus huanglongbing disease. Ann. Entomol. Soc. Am. 104:526-533.

9. Aubert, B. 1987. Trioza erytreae del Guercio and Diaphorina citri Kuwayama (Homoptera: Psylloidea), the two vectors of citrus greening disease: Biological aspects and possible control strategies. Fruits 42:149162.

10. Aubert, B. 1993. Citrus greening disease, a serious limiting factor for citri culture in Asia and Africa. Pages 134-142 in: Proc. 4th Cong. Int. Soc. Citrus Nurserymen. R. Etienne, ed., South Africa.

11. Aubert, B., and Quilici, S. 1988. Monitoring adult psyllas on yellow traps in Reunion Island. Pages 249-254 in: Proc. 10th Conf. Int. Organ. Citrus
Virol. S. M. Garnsey, L. W. Timmer, and J. A. Dodds, eds. International Organization of Citrus Virologists, Riverside, CA.

12. Auh, C. K., and Murphy, T. M. 1995. Plasma membrane redox enzyme is involved in the synthesis of $\mathrm{O}_{2}^{-}$and $\mathrm{H}_{2} \mathrm{O}_{2}$ by Phytophthora elicitorstimulated rose cells. Plant Physiol. 107:1241-1247.

13. Bai, X., Zhang, J., Ewing, A., Miller, S. A., Jancso Radek, A., Shevchenko, D. V., Tsukerman, K., Walunas, T., Lapidus, A., Campbell, J. W., and Hogenhout, S. A. 2006. Living with genome instability: The adaptation of phytoplasmas to diverse environments of their insect and plant hosts. J. Bacteriol. 188:3682-3696.

14. Bassanezi, R. B., Montesino, L. H., and Stuchi, E. S. 2009. Effects of huanglongbing on fruit quality of sweet orange cultivars in Brazil. Eur. J. Plant Pathol. 125:565-572.

15. Bastianel, C., Garnier-Semancik, M., Renaudin, J., Bové, J. M., and Eveillard, S. 2005. Diversity of 'Candidatus Liberibacter asiaticus', based on the omp gene sequence. Appl. Environ. Microbiol. 71:6473-6478.

16. Basu, B., and Apte, S.K. 2008. A novel serralysin metalloprotease from Deinococcus radiodurans. Biochim. Biophys. Acta 1784:1256-1264.

17. Belas, R., Manos, J., and Suvanasuthi, R. 2004. Proteus mirabilis ZapA metalloprotease degrades a broad spectrum of substrates, including antimicrobial peptides. Infect. Immun. 72:5159-5167.

18. Bhagabati, K. N. 1993. Survey of greening disease of mandarin orange in the northeastern states of India. Pages 441-442 in: Proc. 12th Conf. Int. Organ. Citrus Virol. P. Moreno, J. V. da Graça, and L. W. Timmer, eds. University of California, Riverside.

19. Bhattacharyya, A., Stilwagen, S., Ivanova, N., D’Souza, M., Bernal, A., Lykidis, A., Kapatral, V., Anderson, I., Larsen, N., Los, T., Reznik, G., Selkov, E., Jr., Walunas, T. L., Feil, H., Feil, W. S., Purcell, A., Lassez, J. L., Hawkins, T. L., Haselkorn, R., Overbeek, R., Predki, P. F., and Kyrpides, N. C. 2002. Whole-genome comparative analysis of three phytopathogenic Xylella fastidiosa strains. Proc. Natl. Acad. Sci. USA 99:12403-12408.

20. Bové, J. M. 2006. Huanglongbing: A destructive, newly-emerging, century-old disease of citrus. J. Plant Pathol. 88:7-37.

21. Bové, J. M., Renaudin, J., Saillard, C., Foissac, X., and Garnier, M. 2003. Spiroplasma citri, a plant pathogenic mollicute: Relationships with its two hosts, the plant and the leafhopper vector. Annu. Rev. Phytopathol. 41:483-500.

22. Buitendag, C. H., and von Broembsen, L. A. 1993. Living with citrus greening in South Africa. Citrus J. 3:29-32.

23. Capoor, S. P., Rao, D. G., and Viswanath, S. M. 1967. Diaphorina citri Kuway., a vector of the greening disease of citrus in India. Indian J. Agric. Sci. 37:572-576.

24. Capoor, S. P., Rao, D. G., and Viswanath, S. M. 1974. Greening disease of citrus in the Deccan Trap Country and its relationship with the vector, Diaphorina citri Kuwayama. Pages 43-49 in: Proc. 6th Conf. Int. Citrus Virol. L. G. Weathers and M. Cohen, eds. University of California, Division of Agricultural Sciences, CA.

25. Castro, M. S., and Fontes, W. 2005. Plant defense and antimicrobial peptides. Protein Peptide Lett. 12:11-16.

26. Chen, J., Deng, X., Sun, X., Jones, D., Irey, M., and Civerolo, E. 2010. Guangdong and Florida populations of 'Candidatus Liberibacter asiaticus' distinguished by a genomic locus with short tandem repeats. Phytopathology 100:567-572.

27. Chen, J., Pu, X., Deng, X., Liu, S., Li, H., and Civerolo, E. 2009. A phytoplasma related to 'Candidatus Phytoplasma asteris' detected in citrus showing huanglongbing (yellow shoot disease) symptoms in Guangdong, P. R. China. Phytopathology 99:236-242.

28. Chino, M., Hayashi, H., Nakamura, S., Oshima, T., Turner, H., Sabnis, D., Borkovec, V., Baker, D., Girouse, G., Bonnemain, C. L., and Delrot, S. 1991. Phloem sap composition. Pages 64-73 in: Recent Advances in Phloem Transport and Assimilate Compartmentation. J. L. Bonnemain, S. Delrot, W. J. Lucas, and J. Dainty, eds. Nantes Cedex: Ouest Editions. Nantes, France.

29. Cong, Q., Kinch, L. N., Kim, B.-H., and Grishin, N. V. 2012. Predictive sequence analysis of the 'Candidatus Liberibacter asiaticus' proteome. PLOS ONE 7:e41071.

30. da Graça, J. V. 1991. Citrus greening disease. Annu. Rev. Phytopathol. 29:109-136.

31. Dagulo, L., Danyluk, M. D., Spann, T. M., Valim, M. F., GoodrichSchneider, R., Sims, C., and Rouseff, R. 2010. Chemical characterization of orange juice from trees infected with citrus greening (huanglongbing). J. Food Sci. 75:C199-C207.

32. Dahler, G. S., Barras, F., and Keen, N. T. 1990. Cloning of genes encoding extracellular metalloproteases from Erwinia chrysanthemi EC16. J. Bacteriol. 172:5803-5815.

33. Damsteegt, V., Postnikova, E., Stone, A., Kuhlmann, M., Wilson, C., Sechler, A., Schaad, N., Brlansky, R. H., and Schneider, W. 2010. The relevance of Murraya paniculata and related species as potential hosts and 
inoculum reservoirs of 'Candidatus Liberibacter asiaticus', causal agent of huanglongbing. Plant Dis. 94:528-533.

34. Deng, X., Lou, Z., Feng, Z., Li, H., Chen, J., and Civerolo, E. L. 2008. First report of Candidatus Liberibacter asiaticus from Atalantia buxifolia in Guangdong, China. Plant Dis. 92:314.

35. Deng, X., Zhou, G., Li, H., Chen, J., and Civerolo, E. L. 2007. Detection of Candidatus Liberibacter asiaticus from wampee (Clausena lanseum Skeels) by nested PCR. Plant Health Prog. Online publication. doi: 10.1094/PHP-2007-0419-01-BR

36. Ding, F., Deng, X., Hong, N., Zhong, Y., Wang, G., and Yi, G. 2009. Phylogenetic analysis of the citrus huanglongbing (HLB) bacterium based on the sequences of $16 \mathrm{~S}$ rDNA and $16 \mathrm{~S} / 23 \mathrm{~S} \mathrm{rDNA}$ intergenic regions among isolates in China. Eur. J. Plant Pathol. 124:495-503.

37. Ding, F., Wang, G., Yi, G., Zhong, Y., Zeng, J., and Zhou, B. 2005. Infection of wampee and lemon by the citrus huanglongbing pathogen ('Candidatus Liberibacter asiaticus') in China. J. Plant Pathol. 87:207212.

38. Doddapaneni, H., Liao, H., Lin, H., Bai, X., Zhao, X., Civerolo, E. L., Irey, M., Coletta-Filho, H., and Pietersen, G. 2008. Comparative phylogenomics and multi-gene cluster analyses of the citrus huanglongbing (HLB)-associated bacterium 'Candidatus Liberibacter'. BMC Res. Notes $1: 72$.

39. Doke, N. 1983. Involvement of superoxide anion generation in the hypersensitive response of potato tuber tissues to infection with an incompatible race of Phytophthora infestans and to the hyphal wall components. Physiol. Plant Pathol. 23:345-357.

40. Duan, Y., Zhou, L., Hall, D. G., Li, W., Doddapaneni, H., Lin, H., Liu, L., Vahling, C. M., Gabriel, D. W., Williams, K. P., Dickerman, A., Sun, Y., and Gottwald, T. 2009. Complete genome sequence of citrus huanglongbing bacterium, 'Candidatus Liberibacter asiaticus' obtained through metagenomics. Mol. Plant-Microbe Interact. 22:1011-1020.

41. Duan, Y. P., Gottwald, T., Zhou, L. J., and Gabriel, D. W. 2008. First report of dodder transmission of 'Candidatus Liberibacter asiaticus' to tomato (Lycopersicon esculentum). Plant Dis. 92:831-831

42. Dunning, F. M., Sun, W., Jansen, K. L., Helft, L., and Bent, A. F. 2007. Identification and mutational analysis of Arabidopsis FLS2 leucine-rich repeat domain residues that contribute to flagellin perception. Plant Cell 19:3297-3313

43. Durrant, W. E., and Dong, X. 2004. Systemic acquired resistance. Annu. Rev. Phytopathol. 42:185-209.

44. Esau, K., and Cheadle, V. I. 1959. Size of pores and their contents in sieve elements of Dicotyledons. Proc. Natl. Acad. Sci. USA 45:156-162.

45. Etxeberria, E., Gonzalez, P., Achor, D., and Albrigo, G. 2009. Anatomical distribution of abnormally high levels of starch in HLB-affected Valencia orange trees. Physiol. Mol. Plant Pathol. 74:76-83.

46. Fan, G.-C., Cai, Z. J., Weng, Q. Y., Ke, C., Liu, B., Zhou, L. J., and Duan, Y.-P. 2011. First report of a new host (Pithecellobium lucidum Benth) of the citrus huanglongbing bacterium, Candidatus Liberibacter asiaticus. Page 137 in: 2nd Int. Conf. Huanglongbing. Orlando, FL.

47. Fan, J., Chen, C., Brlansky, R. H., Gmitter, F. G., Jr., and Li, Z. G. 2010. Changes in carbohydrate metabolism in Citrus sinensis infected with 'Candidatus Liberibacter asiaticus'. Plant Pathol. 59:1037-1043.

48. Fan, J., Chen, C., Yu, Q., Khalaf, A. A., Achor, D. S., Brlansky, R. H., Moore, G. A., Li, Z.-G., and Gmitter, F. G. 2012. Comparative transcriptional and anatomical analyses of tolerant rough lemon and susceptible sweet orange in response to 'Candidatus Liberibacter asiaticus' infection. Mol. Plant-Microbe Interact. 25:1396-1407.

49. Fletcher, J., Wayad, Y., Melcher, U., and Fengcum, Y. 1998. The phytopathogenic Mollicutes-insect vector interface: A closer look. Phytopathology 88:1351-1358.

50. Flowers, T. J., and Yeo, A. R. 1992. Solute Transport in Plants. Blackie Academic and Professional, New York.

51. Folimonova, S. Y., and Achor, D. S. 2010. Early events of citrus greening (huanglongbing) disease development at the ultrastructural level. Phytopathology 100:949-958.

52. Folimonova, S. Y., Robertson, C. J., Garnsey, S. M., Gowda, S., and Dawson, W. O. 2009. Examination of the responses of different genotypes of citrus to huanglongbing (citrus greening) under different conditions. Phytopathology 99:1346-1354.

53. Furuya, N., Matsukura, K., Tomimura, K., Okuda, M., Miyata, S. I., and Iwanami, T. 2010. Sequence homogeneity of the $\psi$ serA-trmU-tufB-secEnusG-rplKAJL-rpoB gene cluster and the flanking regions of 'Candidatus Liberibacter asiaticus' isolates around Okinawa Main Island in Japan. J. Gen. Plant Pathol. 76:122-131.

54. Gage, D. J. 2004. Infection and invasion of roots by symbiotic, nitrogenfixing rhizobia during nodulation of temperate legumes. Microbiol. Mol. Biol. Rev. 68:280-300.

55. Gao, S., Garnier, M., and Bové, J. M. 1993. Production of monoclonal antibodies recognizing most strains of the greening BLO by in vitro immunization with an antigenic protein purified from the BLO. Pages 244-249 in: Proc. 12th Conf. Int. Organ. Citrus Virol. P. Moreno, J. V. da Graça, and L. W. Timmer, eds. University of California, Riverside.

56. Garnier, M., and Bové, J. M. 1983. Transmission of the organism associated with citrus greening disease from sweet orange to periwinkle by dodder. Phytopathology 73:1358-1363.

57. Garnier, M., Jagoueix-Eveillard, S., Cronje, P. R., Le Roux, H. F., and Bové, J. M. 2000. Genomic characterization of a liberibacter present in an ornamental rutaceous tree, Calodendrum capense, in the Western Cape Province of South Africa. Proposal of 'Candidatus Liberibacter africanus subsp. capensis'. Int. J. Syst. Evol. Microbiol. 50:2119-2125.

58. Garnier, M., Martin-Gros, G., and Bové, J. M. 1987. Monoclonal antibodies against the bacterial-like organism associated with citrus greening disease. Ann. Inst. Pasteur Microbiol. 138:639-650.

59. Gomez-Cardenas, A., Mehouachi, J., Tadeo, F. R., Primo-Millo, E., and Talon, M. 2000. Hormonal regulation of fruitlet abscission induced by carbohydrate shortage in citrus. Planta 210:636-643.

60. Gotoh, H., Kasaraneni, N., Devineni, N., Dallo, S. F., and Weitao, T. 2010. SOS involvement in stress-inducible biofilm formation, Biofouling 26:603-611.

61. Gottwald, T. R. 2010. Current epidemiological understanding of citrus huanglongbing. Annu. Rev. Phytopathol. 48:119-139.

62. Gouaux, E. 1998. alpha-Hemolysin from Staphylococcus aureus: An archetype of beta-barrel, channel-forming toxins. J. Struct. Biol. 121:110122.

63. Grant, J. J., Yun, B. W., and Loake, G. J. 2000. Oxidative burst and cognate redox signalling reported by luciferase imaging: Identification of a signal network that functions independently of ethylene, SA and Me-JA but is dependent on MAPKK activity. Plant J. 24:569-582.

64. Gudesblat, G. E., Torres, P. S., and Vojnov, A. A. 2009. Xanthomonas campestris overcomes Arabidopsis stomatal innate immunity through a DSF cell-to-cell signal-regulated virulence factor. Plant Physiol. 149: 1017-1027.

65. Halbert, S. E., and Manjunath, K. L. 2004. Asian citrus psyllids (Sternorrhyncha: Psyllidae) and greening disease of citrus: A literature review and assessment of risk in Florida. Fla. Entomol. 87:330-353.

66. Hartung, J. S., Paul, C., Achor, D., and Brlansky, R. H. 2010. Colonization of dodder, Cuscuta indecora, by 'Candidatus Liberibacter asiaticus' and 'Ca. L. americanus'. Phytopathology 100:756-762.

67. Hartung, J. S., Shao, J., and Kuykendall, L. D. 2011. Comparison of the ' $C a$. Liberibacter asiaticus' genome adapted for an intracellular lifestyle with other members of the Rhizobiales. PLoS One 6:e23289.

68. Hilf, M. E. 2011. Colonization of citrus seed coats by 'Candidatus Liberibacter asiaticus': Implications for seed transmission of the bacterium. Phytopathology 101:1242-1250.

69. Hu, W. Z., Wang, X. F., Zhou, Y., Li, Z. A., Tang, K. Z., and Zhou, C. Y. 2011. Diversity of the omp gene in 'Candidatus Liberibacter asiaticus' in China. J. Plant Pathol. 93:211-214.

70. Huang, C. H., and Chang, C. A. 1980. Studies on the relation of mycoplasma-like organism with the decline of Wentan pummelo in Taiwan. J. Agric. Res. China 29:13-19.

71. Hung, T. H., Hung, S. C., Chen, C. N., Hsu, M. S., and Su, H. J. 2004. Detection by PCR of 'Candidatus Liberibacter asiaticus', the bacterium causing citrus huanglongbing in vector psyllids: Application to the study of vector-pathogen relationships. Plant Pathol. 53:96-102.

72. Hung, T. H., Wu, M. L., and Su, H. J. 2000. Identification of alternative hosts of the fastidious bacterium causing citrus greening disease. J. Phytopathol. 148:321-326.

73. Hung, T. H., Wu, M. L., and Su, H. J. 2001. Identification of the Chinese box orange (Severinia buxifolia) as an alternative host of the bacterium causing citrus huanglongbing. Eur. J. Plant Pathol. 107:183-189.

74. Inoue, H., Ohnishi, J., Ito, T., Tomimura, K., Miyata, S., Iwanami, T., and Ashihara, W. 2009. Enhanced proliferation and efficient transmission of 'Candidatus Liberibacter asiaticus' by adult Diaphorina citri after acquisition feeding in the nymphal stage. Ann. Appl. Biol. 155:29-36.

75. Jagoueix, S., Bové, J. M., and Garnier, M. 1994. The phloem-limited bacterium of greening disease of citrus is a member of the alpha subdivision of the Proteobacteria. Int. J. Syst. Bacteriol. 44:379-386.

76. Johnson E., Bright D. B., and Graham J. H. 2012. Early root infection and damage in citrus huanglongbing disease development. Phytopathology 102:S4.59.

77. Jones, J. D., and Dangl, J. L. 2006. The plant immune system. Nature 444:323-329.

78. Katagiri, F., and Tsuda, K. 2010. Understanding the plant immune system. Mol. Plant-Microbe Interact. 23:1531-1536.

79. Katoh, H., Davis, R., Smith, M. W., Weinert, M., and Iwanami, T. 2012. Differentiation of Indian, East Timorese, Papuan and Floridian 'Candidatus Liberibacter asiaticus' isolates on the basis of simple sequence repeat and single nucleotide polymorphism profiles at 25 loci. Ann. Appl. 
Biol. 160:291-297.

80. Katoh, H., Subandiyah, S., Tomimura, K., Okuda, M., Su, H. J., and Iwanami, T. 2011. Differentiation of 'Candidatus Liberibacter asiaticus' isolates by variable-number tandem-repeat analysis. Appl. Environ. Microbiol. 77:1910-1917.

81. Kim, J. S., Sagaram, U. S., Burns, J. K., Li, J. L., and Wang, N. 2009. Response of sweet orange (Citrus sinensis) to 'Candidatus Liberibacter asiaticus' infection: Microscopy and microarray analyses. Phytopathology 99:50-57.

82. Koh, E. J., Zhou, L., Williams, D. S., Park, J., Ding, N., Duan, Y. P., and Kang, B. H. 2011. Callose deposition in the phloem plasmodesmata and inhibition of phloem transport in citrus leaves infected with 'Candidatus Liberibacter asiaticus'. Protoplasma 249:687-697.

83. Koizumi, M., Prommintara, M., Linwattana, G., and Kaisuwan, T. 1993. Field evaluation of citrus cultivars for greening resistance in Thailand. Pages 274-279 in: Proc. 12th Conf. Int. Organ. Citrus Virol. P. Moreno, J. V. da Graça, and L. W. Timmer eds. University of California, Riverside.

84. Konstantinidis, K. T., Ramette, A., and Tiedje, J. M. 2006. The bacterial species definition in the genomic era. Philos. Trans. R. Soc. Lond. B. Biol. Sci. 361:1929-1940

85. Korsten, L. S., Jagoueix, Bové, J. M., and Garnier, M. 1996. huanglongbing (greening) detection in South Africa. Pages 395-398 in: Proc. 13th Conf. Int. Organ. Citrus Virol. (IOCV). J. V. da Graça, P. Moreno, and R. K. Yokomi, eds. University of California, Riverside.

86. Kube, M., Schneider, B., Kuhl, H., Dandekar, T., Heitmann, K., Migdoll, A.M., Reinhardt, R., and Seemüller, E. 2008. The linear chromosome of the plant-pathogenic mycoplasma 'Candidatus Phytoplasma mali'. BMC Genomics 9:306.

87. Kuykendall, L. D., Shao, J. Y., and Hartung, J. S. 2012. 'Ca. Liberibacter asiaticus' proteins orthologous with pSymA-encoded proteins of Sinorhizobium meliloti: Hypothetical roles in plant host interaction. PLoS One 7:e38725.

88. Lally, E. T., Hill, R. B., Kieba, I. R., and Korostoff, J. 1999. The interaction between RTX toxins and target cells. Trends Microbiol. 7:356-361.

89. Leonard, M. T., Fagen, J. R., Davis-Richardson, A. G., Davis, M. J., and Triplett, E. W. 2012. Complete genome sequence of Liberibacter crescens BT-1. Stand. Genomic Sci. Online publication. doi:10.4056/ sigs.33267727:2

90. Li, W., Cong, Q., Pei, J., Kinch, L. N., and Grishin, N. V. 2012. The $\mathrm{ABC}$ transporters in 'Candidatus Liberibacter asiaticus'. Proteins 80:2614-2618.

91. Liao, H. L., and Burns, J. K. 2012. Gene expression in Citrus sinensis fruit tissues harvested from huanglongbing-infected trees: Comparison with girdled fruit. J. Exp. Bot. 63:3307-3319.

92. Lin, H., Lou, B., Glynn, J. M., Doddapaneni, H., Civerolo, E. L., Chen, C., Duan, Y., Zhou, L., and Vahling, C. M. 2011. The complete genome sequence of 'Candidatus Liberibacter solanacearum', the bacterium associated with potato zebra chip disease. PLoS One 6:e19135.

93. Lin, S. J., Ke, Y. F., and Tao, C. C. 1973. Bionomics observation and integrated control of citrus psylla, Diaphorina citri Kuwayama. J. Hortic. Soc. China 19:234-242. (In Chinese, English summary)

94. Liu, R., Zhang, P., Pu, X., Xing, X., Chen, J., and Deng, X. 2011. Analysis of a prophage gene frequency revealed population variation of 'Candidatus Liberibacter asiaticus' from two citrus-growing provinces in China. Plant Dis. 95:431-435.

95. Lopes, S. A., and Frare, G. F. 2008. Graft transmission and cultivar reaction of citrus to 'Candidatus Liberibacter americanus'. Plant Dis. 92:21-24.

96. Lopes, S. A., Frare, G. F., Camargo, L. E. A., Wulff, N. A., Teixeira, D. C., Bassanezi, R. B., Beattie, G. A. C., and Ayres, A. J. 2010. Liberibacters associated with orange jasmine in Brazil: Incidence in urban areas and relatedness to citrus liberibacters. Plant Pathol. 59:1044-1053.

97. Maeda, H., and Morihara, K. 1995. Serralysin and related bacterial proteinases. Methods Enzymol. 248:395-413.

98. Mann, R. S., Pelz-Stelinski, K., Hermann, S. L., Tiwari, S., and Stelinski, L. L. 2011. Sexual transmission of a plant pathogenic bacterium, 'Candidatus Liberibacter asiaticus', between conspecific insect vectors during mating. PLoS One 6:e29197.

99. Martinelli, F., Uratsu, S. L., Albrecht, U., Reagan, R. L., Phu, M. L., Britton, M., Buffalo, V. Fass, J., Leicht, E., Zhao, W., Lin, D., D’Souza, R., Davis, C. E., Bowman, K. D. and Dandekar, A. M. 2012. Transcriptome profiling of citrus fruit response to huanglongbing disease. PloS One 7:e38039.

100. Massonie, G., Garnier, M., and Bové, J. M. 1976. Transmission of Indian citrus decline by Trioza erytreae, the vector of South African greening. Pages 18-20 in: Proc. 7th Conf. Int. Organ. Citrus Virol. E. C. Calavan, ed. University of California, Riverside.
101. Matsumoto, T. M., Wang, M. C., and Su, H. J. 1961. Studies on Likubin. Pages 121-125 in: Proc. Second Conf. Int. Organ. Citrus Virol. W. C. Price, ed. University of Florida, Gainesville.

102. Melotto, M., Underwood, W., Koczan, J., Nomura, K., and He, S. Y. 2006. Plant stomata function in innate immunity against bacterial invasion. Cell 126:969-980.

103. Meyer, J. M., and Hoy, M. A. 2008. Molecular survey of endosymbionts in Florida populations of Diaphorina citri (Hemiptera: Psyllidae) and its parasitoids Tamarixia radiata (Hymenoptera: Eulophidae) and Diaphorencyrtus aligarhensis (Hymenoptera: Encyrtidae). Fla. Entomol. 91:294-304.

104. Miyata, S. I., Kato, H., Davis, R., Smith, M. W., Weinert, M., and Iwanami, T. 2011. Asian-common strains of 'Candidatus Liberibacter asiaticus' are distributed in Northeast India, Papua New Guinea and Timor-Leste. J. Gen. Plant Pathol. 77:43-47.

105. Moran, N. A., McCutcheon, J. P., and Nakabachi, A. 2008. Genomics and evolution of heritable bacterial symbionts. Annu. Rev. Genet. 42:165-190.

106. Moriwaki, N., Matsushita, K., Nishina, M., Matsuda, K., and Kono, Y. 2003. High myo-inositol concentration in the hemolymph of planthoppers. Appl. Entomol. Zool. 38:359-364.

107. Moya, A., Peretó, J., Gil, R., and Latorre, A. 2008. Learning how to live together: Genomic insights into prokaryote-animal symbioses. Nat. Rev. Genet. 9:218-229.

108. Mucyn, T. S., Clemente, A., Andriotis, V. M., Balmuth, A. L., Oldroyd, G. E., Staskawicz, B. J., and Rathjen, J. P. 2006. The tomato NBARCLRR protein Prf interacts with Pto kinase in vivo to regulate specific plant immunity. Plant Cell 18:2792-2806.

109. Musetti, R., Paolacci, A., Ciaffi, M., Tanzarella, O. A., Polizzotto, R., Tubaro, F., Mizzau, M., Ermacora, P., Badiani, M., and Osler, R. 2010. Phloem cytochemical modification and gene expression following the recovery of apple plants from apple proliferation disease. Phytopathology 100:390-399.

110. Nadarasah, G., and Stavrinides, J. 2011. Insects as alternative hosts for phytopathogenic bacteria. FEMS Microbiol. Rev. 35:555-575.

111. Naito, K., Taguchi, F., Suzuki, T., Inagaki, Y., Toyoda, K., Shiraishi, T., and Ichinose, Y. 2008. Amino acid sequence of bacterial microbeassociated molecular pattern flg22 is required for virulence. Mol. PlantMicrobe Interact. 21:1165-1174.

112. Nicaise, V., Roux, M., and Zipfel, C. 2009. Recent advances in PAMPtriggered immunity against bacteria: Pattern recognition receptors watch over and raise the alarm. Plant Physiol. 150:1638-1647.

113. Orozco-Cardenas, M., and Ryan, C.A. 1999. Hydrogen peroxide is generated systemically in plant leaves by wounding and systemin via the octadecanoid pathway. Proc. Natl. Acad. Sci. USA 96:6553-6557.

114. Pelz-Stelinski, K. S., Brlansky, R. H., Ebert, T. A., and Rogers, M. E. 2010. Transmission parameters for 'Candidatus Liberibacter asiaticus' by Asian citrus psyllid (Hemiptera: Psyllidae). J. Econ. Entomol. 103:1531-1541.

115. Ramadugu, C., Manjunah, K. L., Halbert, S. E., Brlansky, R. H., Roose, M., and Lee, R. F. 2010. Characterization of huanglongbing associated 'Candidatus Liberibacter asiaticus' from citrus relatives. (Abstr.) Phytopathology 100:S107.

116. Rosales, R., and Burns, J. K. 2011. Phytohormone changes and carbohydrate status in sweet orange fruit from huanglongbing-infected trees. J. Plant Growth Regul. 30:312-321.

117. Sagaram, U. S., DeAngelis, K. M., Trivedi, P., Andersen, G. L., Lu, S. E., and Wang, N. 2009. Bacterial diversity analysis of huanglongbing pathogen-infected citrus, using PhyloChip arrays and 16S rRNA gene clone library sequencing. Appl. Environ. Microbiol. 75:1566-1574.

118. Schmidtchen, A., Frick, I. M., Andersson, E., Tapper, H., and Bjorck, L. 2002. Proteinases of common pathogenic bacteria degrade and inactivate the antibacterial peptide LL-37. Mol. Microbiol. 46:157-168.

119. Schneider, H. 1968. Anatomy of greening diseased sweet orange shoots. Phytopathology 58:1155-1160.

120. Schneider, H. 1968. The anatomy of citrus. Pages 1-85 in: The Citrus Industry. W. Reuther, L. D. Batchelor, and H. J. Webber, eds. University of California Press, Berkeley.

121. Sexton, R., and Roberts, J. A. 1982. Cell biology of abscission. Annu. Rev. Plant Physiol. 33:133-162.

122. Shah, J. 2003. The salicylic acid loop in plant defense. Curr. Opin. Plant Biol. 6:365-371.

123. Shokrollah, H., Abdullah, T. L., Sijam, K., Abdullah, S. N. A., and Abdullah., N. A. P. 2009. Differential reaction of citrus species in Malaysia to huanglongbing (HLB) disease using grafting method. Am. J. Agric. Biol. Sci. 4:32-38.

124. Stoebner, J. A., and Payne, S. M. 1988. Iron-regulated hemolysin production and utilization of heme and hemoglobin by Vibrio cholerae. Infect. Immun. 56:2891-2895. 
125. Su, H. J., and Wu, R. Y. 1979. Preliminary study on the etiology of Wentan pomelo decline. Natl. Sci. Counc. Symp. 1:143-152.

126. Subandiyah, S., Nikoh, N., Tsuyumu, S., Somowiyarjo, S., and Fukatsu, T. 2000. Complex endosymbiotic microbiota of the citrus psyllid Diaphorina citri (Homoptera: Psylloidea). Zool. Sci. 17:983-989.

127. Tatineni, S., Sagaram, U. S., Gowda, S., Robertson, C. J., Dawson, W. O., Iwanami, T., and Wang, N. 2008. In planta distribution of 'Candidatus Liberibacter asiaticus' as revealed by polymerase chain reaction (PCR) and real-time PCR. Phytopathology 98:592-599.

128. Teixeira, D. C., Wulff, N. A., Martins, E. C., Kitajima, E. W., Bassanezi, R., Ayres, A. J., Eveillard, S., Saillard, C., and Bové, J. M. 2008. A phytoplasma closely related to the pigeon pea witches'-broom phytoplasma (16Sr IX) is associated with citrus huanglongbing symptoms in the state of São Paulo, Brazil. Phytopathology 98:977-984.

129. Toft, C., and Andersson, S. G. 2010. Evolutionary microbial genomics: Insights into bacterial host adaptation. Nat. Rev. Genet. 11:465-475.

130. Tomimura, K., Furuya, N., Miyata, S., Hamashima, A., Torigoe, H., Murayama, Y., Kawano, S., Okuda, M., Subaniyah, S., Su, H. J., and Iwanami, T. 2010. Distribution of two distinct genotypes of citrus greening organism in the Ryukyu Islands of Japan. Jpn. Agric. Res. Q. 44:151-158

131. Trivedi, P., Duan, Y., and Wang, N. 2010. Huanglongbing, a systemic disease, restructures the bacterial community associated with citrus roots. Appl. Environ. Microbiol. 76:3427-3436.

132. Trivedi, P., He, Z., Van Nostrand, J. D., Albrigo, G., Zhou, J., and Wang, N. 2012. Huanglongbing alters the structure and functional diversity of microbial communities associated with citrus rhizosphere. ISME J. 6:363-383.

133. Trivedi, P., Sagaram, U. S., Kim, J. S., Brlansky, R. H., Rogers, M. E., Stelinski, L. L., Oswalt, C., and Wang, N. 2009. Quantification of viable 'Candidatus Liberibacter asiaticus' in hosts using quantitative PCR with the aid of ethidium monoazide (EMA). Eur. J. Plant Pathol. 124:553563.

134. Trivedi, P., Spann, T., and Wang, N. 2011. Isolation and characterization of beneficial bacteria associated with citrus roots in Florida. Microbial Ecol. 62:324-336.

135. Trivedi, P., and Wang, N. 2010. Characterization of salicylate hydroxylase of "Candidatus Liberibacter asiaticus" and its role in plant defence suppression (Abstr.) Phytopathology 100:S127.

136. Trivedi P., and Wang, N. 2012. Modulation of plant defense responses by salicylate hydroxylase of 'Candidatus Liberibacter asiaticus' and its implication on canker pathogen Xanthomonas citri subsp. citri in huanglongbing-infected plants. (Abstr.) Phytopathology 102:S4.121.

137. Tsai, C. H., Hung, T. H., and Su, H. J. 2008. Strain identification and distribution of citrus huanglongbing bacteria in Taiwan. Bot. Stud. 49:49-56.

138. Tsai, C. H., Su, H. J., Liao, Y. C., and Hung, T. H. 2006. First report of the causal agent of huanglongbing ('Candidatus Liberibacter asiaticus') infecting kumquat in Taiwan. Plant Dis. 90:1360.

139. Tsai, J. H., and Liu, Y. H. 2000. Biology of Diaphorina citri (Homoptera: Psyllidae) on four host plants. J. Econ. Entomol. 93:1721-1725.

140. Tsai, J. H., Wang, J. J., and Liu, Y. H. 2002. Seasonal abundance of the Asian citrus psyllid, Diaphorina citri (Homoptera: Psyllidae) in Southern Florida. Fla. Entomol. 85:446-451.

141. Tyler, H. L., Roesch, L. F., Gowda, S., Dawson, W. O., and Triplett, E. W. 2009. Confirmation of the sequence of 'Candidatus Liberibacter asiaticus' and assessment of microbial diversity in huanglongbinginfected citrus phloem using a metagenomic approach. Mol. PlantMicrobe Interact. 22:1624-1634.

142. Vahling, C. M., Duan, Y., and Lin, H. 2010. Characterization of an ATP translocase identified in the destructive plant pathogen 'Candidatus Liberibacter asiaticus'. J. Bacteriol. 192:834-840.

143. Vahling-Armstrong, C. M., Zhou, H., Benyon, L., Morgan, J. K., and Duan, Y. 2012. Two plant bacteria, S. meliloti and ' $\mathrm{Ca}$. Liberibacter asiaticus', share functional znuABC homologues that encode for a high affinity zinc uptake system. PloS One 7:e37340.

144. van Den Berg, M. A., van Vuuren, S. P., and Deacon, S. E. 1992. Studies on greening disease transmission by the citrus Psylla, Trioza erytreae (Hemiptera: Triozidae). Israel J. Entomol. 25-26:51-56.

145. van Dongen, J. T., Schurr, U., Pfister, M., and Geigenberger, P. 2003. Phloem metabolism and function have to cope with low internal oxygen. Plant Physiol. 131:1529-1543.

146. van Loon, L. C., Bakker, P. A. H. M., and Pieterse, C. M. J. 1998. Systemic resistance induced by rhizosphere bacteria. Annu. Rev. Phytopathol. 36:453-483.

147. van Wees, S., and Glazebrook, J. 2003. Loss of non-host resistance of Arabidopsis NahG to Pseudomonas syringae pv. phaseolicola is due to degradation products of salicylic acid. Plant J. 33:733-742.

148. Walter, A. J., Hall, D. G., Duan, Y.-P. 2012. Low incidence of 'Candidatus Liberibacter asiaticus' in Murraya paniculata and associated Diaphorina citri. Plant Dis. Online publication. doi:10.1094/PDIS-0811-0668

149. Wang, X., Zhou, C., Deng, X., Su, H., and Chen, J. 2012. Molecular characterization of a mosaic locus in the genome of 'Candidatus Liberibacter asiaticus'. BMC Microbiol. 12:18.

150. Wernegreen, J. J. 2002. Genome evolution in bacterial endosymbionts of insects. Nat. Rev. Genet. 3:850-861.

151. Williamson, D. L., Whitcomb, R. F., Tully, J. G., Gasparich, G. E., Rose, D. L., Carle, P., Bové, J. M., Hackett, K. J., Adams, J. R., Henegar, R. B., Konai, M., Chastel, C., and French, F. E. 1998. Revised group classification of the genus Spiroplasma. Int. J. Syst. Bacteriol. 48:1-12.

152. Winkler, H. H. 1976. Rickettsial permeability. An ADP-ATP transport system. J. Biol. Chem. 251:389-396.

153. Xu, C. F., Xia, Y. H., Li, K. B., and Ke, C. 1988. Further study of the transmission of citrus huanglongbing by a psyllid, Diaphorina citri Kuwayama Pages 243-248 in: Proc. 10th Conf. Int. Organ. Citrus Virol. L. W. Timmer, S. M. Garnsey, and L. Navarro, eds. University of California, Riverside.

154. Yan, Q., Sreedharan, A., Wei, S., Wang, J., Pelz-Stelinski, K., Folimonova, S., and Wang, N. 2013. Global gene expression changes in 'Candidatus Liberibacter asiaticus' during the transmission in distinct hosts between plant and insect. Mol. Plant Pathol. 14:391-404.

155. Zhang, M., Duan, Y., Zhou, L., Turechek, W. W., Stover, E., and Powell, C. A. 2010. Screening molecules for control of citrus huanglongbing using an optimized regeneration system for 'Candidatus Liberibacter asiaticus'-infected Periwinkle (Catharanthus roseus) cuttings. Phytopathology 100:239-245.

156. Zhang, S., Flores-Cruz, Z., Zhou, L., Kang, B. H., Fleites, L. A., Gooch, M. D., Wulff, N. A., Davis, M. J., Duan, Y. P., and Gabriel, D. W. 2011. 'Ca. Liberibacter asiaticus' carries an excision plasmid prophage and a chromosomally integrated prophage that becomes lytic in plant infections. Mol. Plant-Microbe Interact. 24:458-468.

157. Zhou, L., Powell, C. A., Hoffman, M. T., Li, W., Fan, G., Liu, B., Lin, H., and Duan, Y. 2011. Diversity and plasticity of the intracellular plant pathogen and insect symbiont 'Candidatus Liberibacter asiaticus' as revealed by hypervariable prophage genes with intragenic tandem repeats. Appl. Environ. Microbiol. 77:6663-6673.

158. Zhou, L. J., Gabriel, D. W., Duan, Y. P., Halbert, S. E., and Dixon, W. N. 2007. First report of dodder transmission of huanglongbing from naturally infected Murraya paniculata to citrus. Plant Dis. 91:227-227.

159. Zimmermann, M. H., and Ziegler, H. 1975. List of sugars and sugar alcohols in sieve-tube exudates. Pages 245-271 in: Encyclopedia of Plant Physiology, Vol. 1. Transport in Plants. M. H. Zimmermann and J. A. Milburn, eds. Springer-Verlag, New York.

160. Zou, H., Gowda, S., Zhou, L., Hajeri, S., Chen, G., and Duan, Y. P. 2012. The destructive citrus pathogen, 'Candidatus Liberibacter asiaticus' encodes a functional flagellin characteristic of a pathogen-associated molecular pattern. PLoS One 7:e46447. 